\title{
The Coupling Dynamic Analysis and Field Test of TBM Main System under Multipoint Impact Excitation
}

\author{
Junzhou Huo,, Hanyang Wu, ${ }^{1}$ Guangqing Li, ${ }^{1}$ Wei Sun, ${ }^{1}$ and Jing Chen ${ }^{2}$ \\ ${ }^{1}$ School of Mechanical Engineering, Dalian University of Technology, Dalian 116024, China \\ ${ }^{2}$ School of Naval Architecture and Ocean Engineering, Dalian Ocean University, Dalian 116026, China \\ Correspondence should be addressed to Junzhou Huo; huojunzhou@dlut.edu.cn
}

Received 18 December 2014; Accepted 2 June 2015

Academic Editor: Peng Chen

Copyright (c) 2015 Junzhou Huo et al. This is an open access article distributed under the Creative Commons Attribution License, which permits unrestricted use, distribution, and reproduction in any medium, provided the original work is properly cited.

\begin{abstract}
Damage by excessive vibration is serious engineering problem in TBM boring process. Dynamic characteristic analysis is essential for TBM antivibration design. According to TBM horizontal support structure, a dynamic coupling nonlinear model is established, with consideration of time-varying impact load and multicomponent complex relationship from cutter to gripper shoe. A set of field vibration tests is set up to accurately collect data under extreme work conditions; then, field data is collected from Liaoning northwest engineering. Field data is applied to validate simulation model to make sure time-varying damping stiffness, support cylinder stiffness, and the TBM machine stiffness distribution are reasonable. Simulation indicates the weakest part of TBM in axial and torsional DOF is the cylinder hinge and the connection shaft between motor and pinion, and the horizontal and vertical weak parts are bull gear. It also shows that, in normal excavation conditions, the acceleration amplitude of the cutterhead in three directions ranges from $1.5 \mathrm{~g}$ to $2 \mathrm{~g}$. These results provide theoretical basis for the antivibration design and structural optimization of TBM.
\end{abstract}

\section{Introduction}

Full face rock boring machine (TBM) is a symbol product of the equipment manufacturing industry. The design, manufacturing capacity is one of the important symbols to measure a country's development and advanced degree in manufacturing industry [1]. In hard rock, the boring process often accompanies with big torque, thrust, and large impact load. The excessive vibration of TBM will cause nonnormal damage in critical components and shorten the life of TBM. Therefore, studying the vibration characteristics of TBM from the angle of dynamics is quite important.

Domestic and foreign scholars have done a lot of research works in TBM design. Since 1960s, scholars started studying rock crushing mechanism of cutters from different angles such as shear failure and extrusion failure. The rock crushing process is divided into the process of disc cutters intruding into rocks and the formation of rock fragments between two dis cutters $[2,3]$. In order to accurately predict the force on dis cutters in breaking rocks, scholars established a variety of small scale models and set up some force models and calculation formulas, among which Colorado School of Mines (CSM) model is a representative one [46]. Some scholars have detected and analyzed the force on disc cutters in field test. Samuel and Seow [7] studied the change law of force on disc cutters based on a $4.1 \mathrm{~m}$ Robbins cutterhead load test and compared with equipment performance parameters. Zhang et al. [8] performed a load test on a $1.75 \mathrm{~m}$ TBM cutterhead, considering the coupling three-axis force, and proposed a mathematical method of load measurement on disc cutters. The optimal placement design on TBM cutters is one of the most important means to improve the performance of TBM. Large numbers of scholars carried out cutterhead optimization design such as cutter spacing design and cutter layout design. Zhang et al. $[9,10]$ determined the principle of cutter spacing. Xia and Tan [11-13] carried out simulation on cutters breaking rock and obtained the cutting parameters such as optimal cutter spacing and optimal cutting angle in order. Sun and Huo [14-16] proposed cutter layout design method based on genetic algorithm and an idea of coevolutionary, and the optimal design on the main parameters of disc cutters and 


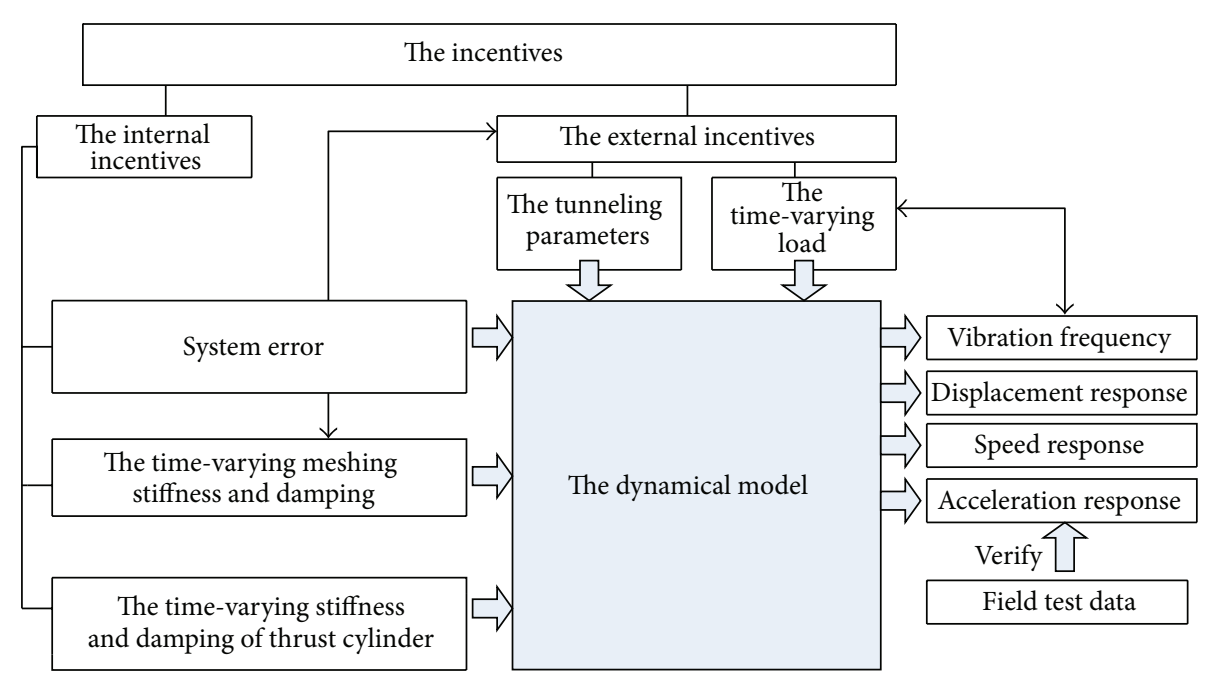

FIGURE 1: Research route.

cutterhead structure was carried out. The researches show that the excessive vibration will not only affect the excavation efficiency but shorten the fatigue life of structural component and lead to the accident [17]. Therefore, many scholars started studying the vibration dynamical characteristics of TBM. Zhang et al. [18-20] established a coupling dynamical model of shield machine considering redundant drive system, hydraulic propulsion system, geological conditions, and so forth, and the dynamical characteristics of the rotary system were studied based on the dynamical model. Sun et al. [21] established a nonlinear dynamical model of cutterhead system and analyzed the dynamical characteristics of cutterhead. Huo et al. [22] presented a multidegree-of-freedom coupling dynamic model for the blocked TBM cutterhead system based on mass centralized method.

In conclusion, the domestic and foreign researches mainly focus on the cutterhead system. These study subjects mainly include rock crushing mechanism, the structural strength and stiffness of cutterhead, the characteristics of random load on cutterhead, and so forth. The study on vibration characteristics mainly focused on the drive system and cutterhead system, and the study on dynamic vibration characteristics of the TBM complete machine was not sufficient. This paper establishes a dynamic coupling nonlinear model of TBM machine, by developing an equivalent method that can accurately simulate dynamical stiffness such as the time-varying meshing stiffness, time-varying support stiffness of thrust cylinder, and bearing stiffness. The research route is shown in Figure 1. This paper provides theoretical basis for the antivibration design and structural optimization of TBM machine.

\section{The Dynamic Coupling Nonlinear Model of TBM Machine}

TBM machine mainly includes cutterhead system and propel system. The cutterhead system includes cutterhead, bull gear, pinion, coupling, variable frequency motor, planetary reducer, and so forth. The propel system includes main frame, support cylinder, and gripper shoe. The component diagram of TBM is shown in Figure 2. $X, Y$, and $Z$ represent horizontal, vertical, and axial direction.

The dynamic model of TBM is shown in Figure 3.

Multidegree-of-freedom coupled nonlinear dynamic equations are as follows.

The horizontal degree of freedom is as follows:

$$
\begin{aligned}
m_{l} \cdot \ddot{X}_{l}= & F_{x}-k_{l r x} \cdot\left(X_{l}-X_{r}\right)-c_{l r x} \cdot\left(\dot{X}_{l}-\dot{X}_{r}\right), \\
m_{r} \cdot \ddot{X}_{r}= & k_{l r x} \cdot\left(X_{l}-X_{r}\right)+c_{l r x} \cdot\left(\dot{X}_{l}-\dot{X}_{r}\right)-k_{r d x} \\
& \cdot\left(X_{r}-X_{d}\right)-c_{r d x} \cdot\left(\dot{X}_{r}-\dot{X}_{d}\right) \\
& -\sum_{i=1}^{10}\left(F_{p r i}+D_{p r i}\right) \cdot \sin \left(\varphi_{i}-\alpha\right), \\
m_{\mathrm{pi}} \cdot \ddot{X}_{\mathrm{pi}}= & \left(F_{p r i}+D_{p r i}\right) \cdot \cos \alpha-k_{p d x} \cdot\left(X_{\mathrm{pi}}-X_{d}\right) \\
& -c_{p d x} \cdot\left(\dot{X}_{\mathrm{pi}}-\dot{X}_{d}\right), \\
m_{d} \cdot \ddot{X}_{d}= & \sum_{i=1}^{10}\left[\left(X_{\mathrm{pi}}-X_{d}\right) \cdot k_{p d x}+\left(\dot{X}_{\mathrm{pi}}-\dot{X}_{d}\right) \cdot c_{p d x}\right] \\
& -k_{d 1 x} \cdot\left(X_{d}-X_{1}\right)-c_{d 1 x} \cdot\left(\dot{X}_{d}-\dot{X}_{1}\right) \\
& +k_{r d x} \cdot\left(X_{r}-X_{d}\right)+c_{r d x} \cdot\left(\dot{X}_{r}-\dot{X}_{d}\right), \\
m_{1} \cdot \ddot{X}_{1}= & k_{d 1 x} \cdot\left(X_{d}-X_{1}\right)+c_{d 1 x} \cdot\left(\dot{X}_{d}-\dot{X}_{1}\right)-k_{12 x} \\
& \cdot\left(X_{1}-X_{2}\right)-c_{12 x} \cdot\left(\dot{X}_{1}-\dot{X}_{2}\right), \\
m_{2} \cdot \ddot{X}_{2}= & k_{12 x} \cdot\left(X_{1}-X_{2}\right)+c_{12 x} \cdot\left(\dot{X}_{1}-\dot{X}_{2}\right)-k_{23 x} \\
& \cdot\left(X_{2}-X_{3}\right)-c_{23 x} \cdot\left(\dot{X}_{2}-\dot{X}_{3}\right), \\
m_{3} \cdot \ddot{X}_{3}= & k_{23 x} \cdot\left(X_{2}-X_{3}\right)+c_{23 x} \cdot\left(\dot{X}_{2}-\dot{X}_{3}\right)-k_{3 r x} \\
& \cdot X_{3}-c_{3 r x} \cdot \dot{X}_{3} .
\end{aligned}
$$




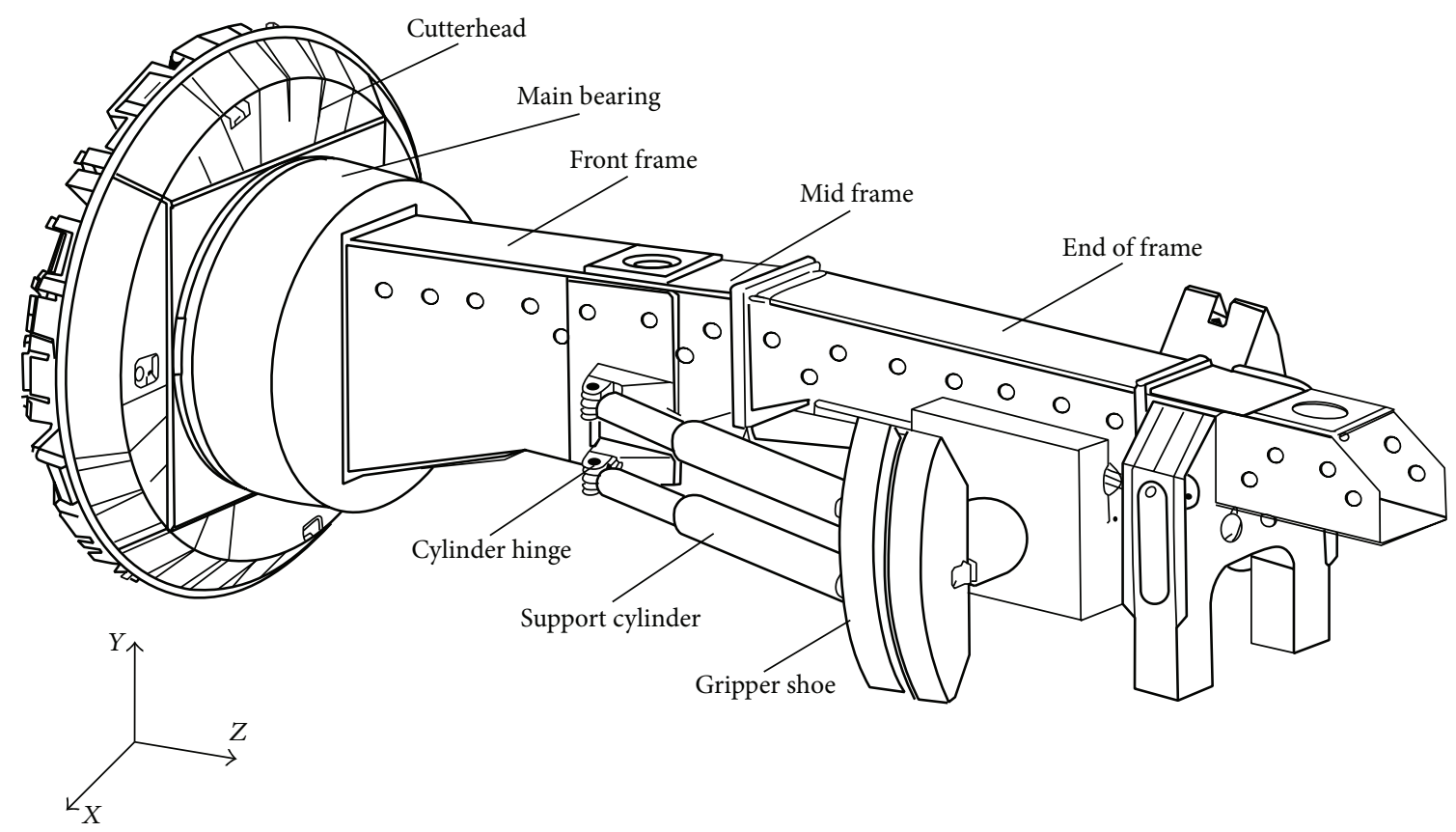

FIgURE 2: The component diagram of TBM.

The vertical degree of freedom is as follows:

$$
\begin{aligned}
m_{l} \cdot \ddot{Y}_{l}= & F_{y}-k_{l r y} \cdot\left(Y_{l}-Y_{r}\right)-c_{l r x} \cdot\left(\dot{Y}_{l}-\dot{Y}_{r}\right), \\
m_{r} \cdot \ddot{Y}_{r}= & k_{l r y} \cdot\left(Y_{l}-Y_{r}\right)+c_{l r y} \cdot\left(\dot{Y}_{l}-\dot{Y}_{r}\right)-k_{r d y} \\
& \cdot\left(Y_{r}-Y_{d}\right)-c_{r d y} \cdot\left(\dot{Y}_{r}-\dot{Y}_{d}\right) \\
& +\sum_{i=1}^{10}\left(F_{p r i}+D_{p r i}\right) \cdot \cos \left(\varphi_{i}-\alpha\right), \\
m_{\mathrm{pi}} \cdot \ddot{Y}_{\mathrm{pi}}= & -\left(F_{p r i}+D_{p r i}\right) \cdot \sin \alpha-k_{p d y} \cdot\left(Y_{\mathrm{pi}}-Y_{d}\right) \\
& -c_{p d y} \cdot\left(\dot{Y}_{\mathrm{pi}}-\dot{Y}_{d}\right), \\
m_{d} \cdot \ddot{Y}_{d}= & \sum_{i=1}^{10}\left[\left(Y_{\mathrm{pi}}-Y_{d}\right) \cdot k_{p d y}+\left(\dot{Y}_{\mathrm{pi}}-\dot{Y}_{d}\right) \cdot c_{p d y}\right] \\
& -k_{d 1 y} \cdot\left(Y_{d}-Y_{1}\right)-c_{d 1 y} \cdot\left(\dot{Y}_{d}-\dot{Y}_{1}\right) \\
& +k_{r d y} \cdot\left(Y_{r}-Y_{d}\right)+c_{r d y} \cdot\left(\dot{Y}_{r}-\dot{Y}_{d}\right), \\
m_{1} \cdot \ddot{Y}_{1}= & k_{d 1 y} \cdot\left(Y_{d}-Y_{1}\right)+c_{d 1 y} \cdot\left(\dot{Y}_{d}-\dot{Y}_{1}\right)-k_{12 y} \\
& \cdot\left(Y_{1}-Y_{2}\right)-c_{12 y} \cdot\left(\dot{Y}_{1}-\dot{Y}_{2}\right), \\
m_{3} \cdot \ddot{Y}_{3}= & k_{23 y} \cdot\left(Y_{2}-Y_{3}\right)+c_{23 y} \cdot\left(\dot{Y}_{2}-\dot{Y}_{3}\right)-k_{3 r y} \\
& \cdot Y_{3}-c_{3 r x} \cdot \dot{Y}_{3} . \\
m_{2} \cdot \ddot{Y}_{2}= & k_{12 y} \cdot\left(Y_{1}-Y_{2}\right)+c_{12 y} \cdot\left(\dot{Y}_{1}-\dot{Y}_{2}\right)-k_{23 y} \\
& \cdot\left(Y_{2}-Y_{3}\right)-c_{23 x} \cdot\left(\dot{Y}_{2}-\dot{Y}_{3}\right), \\
&
\end{aligned}
$$

The axial degree of freedom is as follows:

$$
\begin{aligned}
m_{l} \cdot \ddot{x}_{l}= & F_{L}-k_{l b} \cdot\left(x_{l}-x_{b}\right)-c_{l b} \cdot\left(\dot{x}_{l}-\dot{x}_{b}\right) \\
m_{b} \cdot \ddot{x}_{b}= & k_{l b} \cdot\left(x_{l}-x_{b}\right)+c_{l b} \cdot\left(\dot{x}_{l}-\dot{x}_{b}\right)-k_{b s} \\
& \cdot\left(x_{b}-x_{s}\right)-c_{b s} \cdot\left(\dot{x}_{b}-\dot{x}_{s}\right) \\
m_{s} \cdot \ddot{x}_{s}= & k_{b s} \cdot\left(x_{b}-x_{s}\right)+c_{b s} \cdot\left(\dot{x}_{b}-\dot{x}_{s}\right)-k_{s 1} \\
& \cdot\left(x_{s}-x_{1}\right)-c_{s 1} \cdot\left(\dot{x}_{s}-\dot{x}_{1}\right) \\
m_{1} \cdot \ddot{x}_{1}= & k_{s 1} \cdot\left(x_{s}-x_{1}\right)+c_{s 1} \cdot\left(\dot{x}_{s}-\dot{x}_{1}\right)-k_{12} \\
& \cdot\left(x_{1}-x_{2}\right)-c_{12} \cdot\left(\dot{x}_{1}-\dot{x}_{2}\right)-k_{j 11} \\
& \cdot\left(x_{1} \cdot \cos \theta-x_{j 11}\right) \cdot \cos \alpha-c_{j 11} \\
& \cdot\left(\dot{x}_{1} \cdot \cos \theta-\dot{x}_{j 11}\right) \cdot \cos \theta-k_{j 21} \\
& \cdot\left(x_{1} \cdot \cos \theta-x_{j 21}\right) \cdot \cos \theta-c_{j 21} \\
& \cdot\left(\dot{x}_{1} \cdot \cos \theta-\dot{x}_{j 21}\right) \cdot \cos \theta \\
m_{2} \cdot \ddot{x}_{2}= & k_{12} \cdot\left(x_{1}-x_{2}\right)+c_{12} \cdot\left(\dot{x}_{1}-\dot{x}_{2}\right)-k_{23} \\
& \cdot\left(x_{2}-x_{3}\right)-c_{23} \cdot\left(\dot{x}_{2}-\dot{x}_{3}\right) \\
m_{3} \cdot \ddot{x}_{3}= & k_{23} \cdot\left(x_{2}-x_{3}\right)+c_{23} \cdot\left(\dot{x}_{2}-\dot{x}_{3}\right)-k_{3 r} \cdot x_{3} \\
& -c_{3 r} \cdot \dot{x}_{3}, \\
m_{j 11} \cdot \ddot{x}_{j 11}= & k_{j 11} \cdot\left(x_{1} \cdot \cos \theta-x_{j 11}\right)+c_{j 11} \\
& \cdot\left(\dot{x}_{1} \cdot \cos \theta-\dot{x}_{j 11}\right)-k_{y 11} \\
& \cdot\left(x_{j 11}-x_{j 12}\right)-c_{y 11} \cdot\left(\dot{x}_{j 11}-\dot{x}_{j 12}\right) \\
&
\end{aligned}
$$




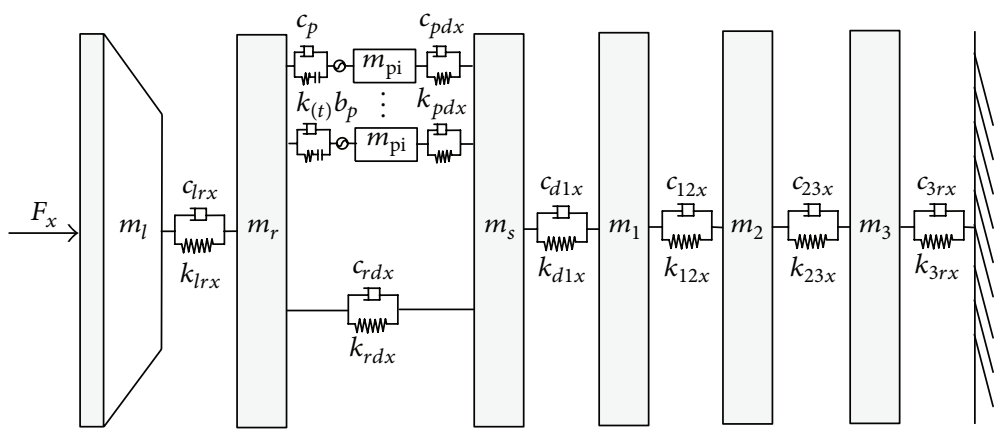

(a) The horizontal degree of freedom

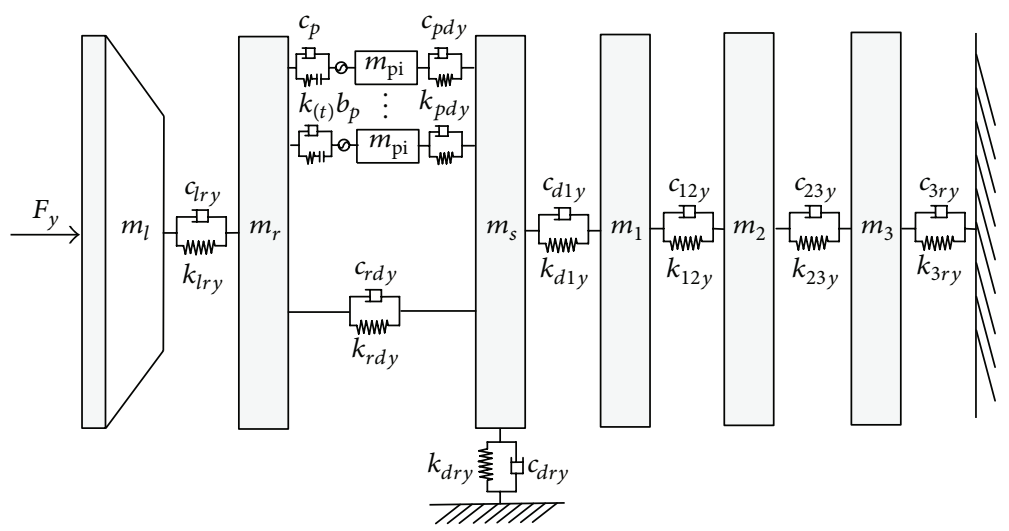

(b) The vertical degree of freedom

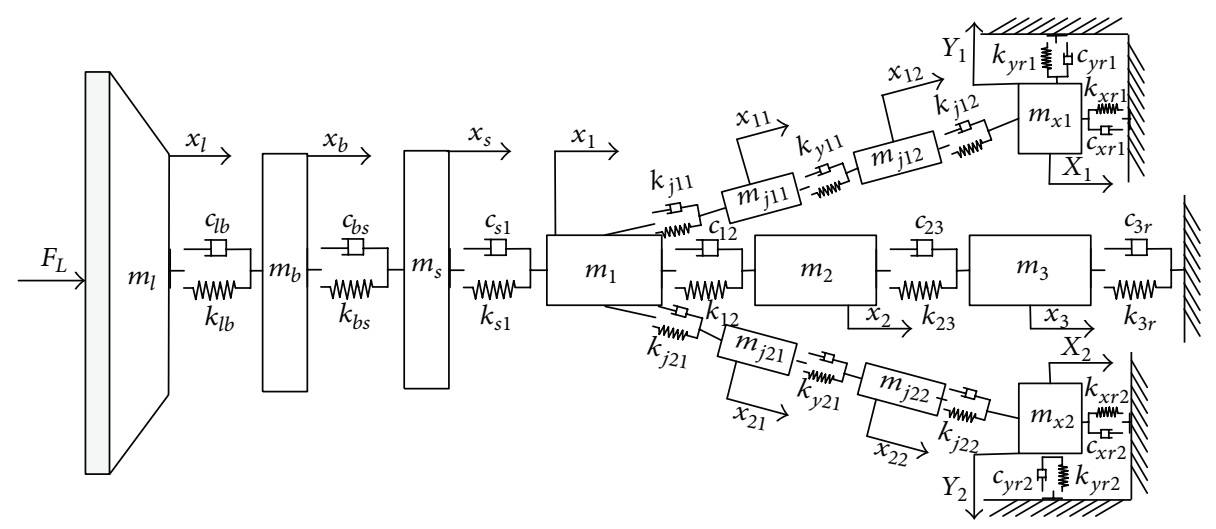

(c) The axial degree of freedom

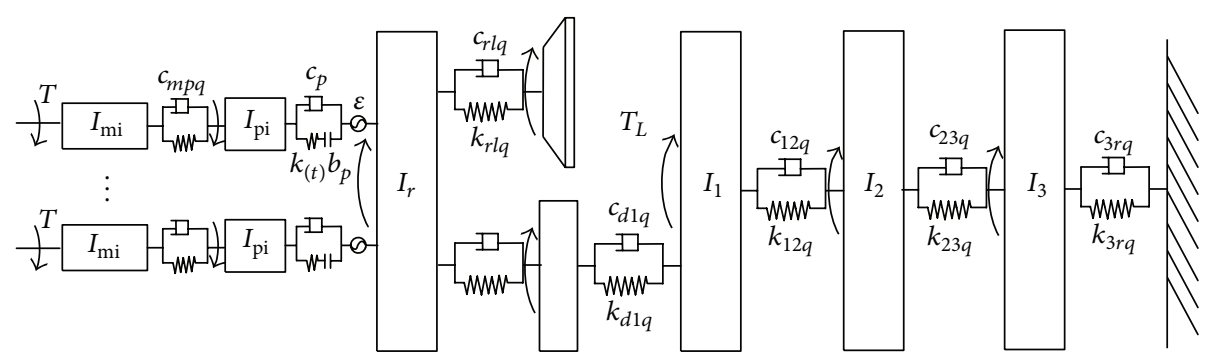

(d) The torsional degree of freedom

FIgURE 3: The dynamic model of TBM. 


$$
\begin{aligned}
& m_{j 21} \cdot \ddot{x}_{j 21}=k_{j 21} \cdot\left(x_{1} \cdot \cos \theta-x_{j 21}\right)+c_{j 21} \\
& \cdot\left(\dot{x}_{1} \cdot \cos \theta-\dot{x}_{j 21}\right)-k_{y 21} \\
& \cdot\left(x_{j 21}-x_{j 22}\right)-c_{y 21} \cdot\left(\dot{x}_{j 21}-\dot{x}_{j 22}\right), \\
& m_{j 12} \cdot \ddot{x}_{j 12}=k_{y 11} \cdot\left(x_{j 11}-x_{j 12}\right)+c_{y 11} \cdot\left(\dot{x}_{j 11}-\dot{x}_{j 12}\right) \\
& -k_{j 12} \cdot\left(x_{j 12}-Y_{1} \cdot \sin \alpha-X_{1} \cdot \cos \theta\right) \\
& -c_{j 12} \\
& \cdot\left(\dot{x}_{j 12}-\dot{Y}_{1} \cdot \sin \theta-\dot{X}_{1} \cdot \cos \theta\right) \text {, } \\
& m_{j 22} \cdot \ddot{x}_{j 22}=k_{y 21} \cdot\left(x_{j 21}-x_{j 22}\right)+c_{y 21} \cdot\left(\dot{x}_{j 21}-\dot{x}_{j 22}\right) \\
& -k_{j 22} \cdot\left(x_{j 22}-Y_{2} \cdot \sin \theta-X_{2} \cdot \cos \theta\right) \\
& -c_{j 22} \\
& \cdot\left(\dot{x}_{j 22}-\dot{Y}_{2} \cdot \sin \theta-\dot{X}_{2} \cdot \cos \theta\right) \text {, } \\
& m_{x 1} \cdot \ddot{X}_{1}=k_{j 12} \cdot\left(x_{j 12}-Y_{1} \cdot \sin \theta-X_{1} \cdot \cos \theta\right) \\
& \cdot \cos \theta+c_{j 12} \\
& \cdot\left(\dot{x}_{j 12}-\dot{Y}_{1} \cdot \sin \theta-\dot{X}_{1} \cdot \cos \theta\right) \\
& \cdot \cos \theta-k_{x r 1} \cdot X_{1}-c_{x r 1} \cdot \dot{X}_{1}, \\
& m_{x 2} \cdot \ddot{X}_{2}=k_{j 22} \cdot\left(x_{j 22}-Y_{2} \cdot \sin \theta-X_{2} \cdot \cos \theta\right) \\
& \cdot \cos \theta+c_{j 22} \\
& \cdot\left(\dot{x}_{j 22}-\dot{Y}_{2} \cdot \sin \theta-\dot{X}_{2} \cdot \cos \theta\right) \\
& \cdot \cos \theta-k_{x r 2} \cdot X_{2}-c_{x r 2} \cdot \dot{X}_{2}, \\
& m_{x 1} \cdot \ddot{Y}_{1}=k_{j 12} \cdot\left(x_{j 12}-Y_{1} \cdot \sin \theta-X_{1} \cdot \cos \theta\right) \\
& \cdot \sin \theta+c_{j 12} \\
& \cdot\left(\dot{x}_{j 12}-\dot{Y}_{1} \cdot \sin \theta-\dot{X}_{1} \cdot \cos \theta\right) \cdot \sin \theta \\
& -k_{y r 1} \cdot Y_{1}-c_{y r 1} \cdot \dot{Y}_{1}, \\
& m_{x 2} \cdot \ddot{Y}_{2}=k_{j 22} \cdot\left(x_{j 22}-Y_{2} \cdot \sin \theta-X_{2} \cdot \cos \theta\right) \\
& \cdot \sin \theta+c_{j 22} \\
& \cdot\left(\dot{x}_{j 22}-\dot{Y}_{2} \cdot \sin \theta-\dot{X}_{2} \cdot \cos \theta\right) \cdot \sin \theta \\
& -k_{y r 2} \cdot Y_{2}-c_{y r 2} \cdot \dot{Y}_{2}
\end{aligned}
$$

The torsional degree of freedom is as follows:

$$
\begin{aligned}
& T_{\mathrm{pi}}-k_{m p q} \cdot\left(\theta_{\mathrm{mi}}-\theta_{\mathrm{pi}}\right)-c_{m p q} \cdot\left(\dot{\theta}_{\mathrm{mi}}-\dot{\theta}_{\mathrm{pi}}\right)=I_{\mathrm{mi}} \cdot \ddot{\theta}_{i}, \\
& k_{m p q} \cdot\left(\theta_{\mathrm{mi}}-\theta_{\mathrm{pi}}\right)+c_{m p q} \cdot\left(\dot{\theta}_{\mathrm{mi}}-\dot{\theta}_{\mathrm{pi}}\right)-\left(F_{p r i}+D_{p r i}\right) \\
& \quad \cdot r_{b p}=I_{\mathrm{pi}} \cdot \ddot{\theta}_{\mathrm{pi}}, \\
& -\sum_{i=1}^{10}\left(F_{p r i}+D_{p r i}\right) \cdot r_{b r}-k_{r l q} \cdot\left(\theta_{r}-\theta_{l}\right)-c_{r l q} \\
& \quad \cdot\left(\dot{\theta}_{r}-\dot{\theta}_{l}\right)-\frac{1}{3} \cdot T_{\mathrm{pi}}=I_{r} \cdot \ddot{\theta}_{r}, \\
& k_{r l q} \cdot\left(\theta_{r}-\theta_{l}\right)+c_{r l q} \cdot\left(\dot{\theta}_{r}-\dot{\theta}_{l}\right)-\frac{2}{3} \cdot T_{\mathrm{pi}}=I_{l} \cdot \ddot{\theta}_{l}, \\
& \frac{1}{3} \cdot T_{\mathrm{pi}}-k_{s 1 q} \cdot\left(\theta_{s}-\theta_{1}\right)-c_{s 1 q} \cdot\left(\dot{\theta}_{s}-\dot{\theta}_{1}\right)=I_{s} \cdot \ddot{\theta}_{s}, \\
& k_{s 1 q} \cdot\left(\theta_{s}-\theta_{1}\right)+c_{s 1 q} \cdot\left(\dot{\theta}_{s}-\dot{\theta}_{1}\right)-k_{12 q} \cdot\left(\theta_{1}-\theta_{2}\right) \\
& \quad-c_{12 q} \cdot\left(\dot{\theta}_{1}-\dot{\theta}_{2}\right)=I_{1} \cdot \ddot{\theta}_{1}, \\
& k_{12 q} \cdot\left(\theta_{1}-\theta_{2}\right)+c_{12 q} \cdot\left(\dot{\theta}_{1}-\dot{\theta}_{2}\right)-k_{23 q} \cdot\left(\theta_{2}-\theta_{3}\right) \\
& -c_{23 q} \cdot\left(\dot{\theta}_{2}-\dot{\theta}_{3}\right)=I_{2} \cdot \ddot{\theta}_{2}, \\
& k_{23 q} \cdot\left(\theta_{2}-\theta_{3}\right)+c_{23 q} \cdot\left(\dot{\theta}_{2}-\dot{\theta}_{3}\right)-k_{3 r q} \cdot \theta_{3}-c_{3 r q} \\
& \quad \dot{\theta}_{3},
\end{aligned}
$$

where $m_{l}, m_{b}, m_{s}, m_{1}, m_{2}, m_{3}, m_{r}, m_{\mathrm{pi}}$ represent the mass of cutterhead, cutterhead bearing, cutterhead support, front frame, mid frame, end of frame, bull gear, and each pinion. $m_{j 11}, m_{j 12}, m_{j 21}, m_{j 22}$ represent the mass of 4 hinges as shown in Figure 3(c). $m_{x 1}, m_{x 2}$ represent the mass of 2 gripper shoes as shown in Figure 3(c). $I_{\mathrm{mi}}, I_{\mathrm{pi}}, I_{r}, I_{l}$ represent the rotary inertia of each motor, each pinion, bull gear, and cutterhead. $k_{j 11}, k_{j 12}, k_{j 21}, k_{j 22}$ represent 4 kinds of stiffness of the corresponding hinges. $k_{x r 1}, k_{y r 1}, k_{x r 2}, k_{y r 2}$ represent the horizontal and axial support stiffness of the corresponding gripper shoes. $k_{l b}, k_{b s}, k_{s 1}, k_{12}, k_{23}, k_{3 r}$ represent the structural stiffness of cutterhead, cutterhead bearing, cutterhead support, front frame, mid frame, and end of frame. $k_{l r x}, k_{r d x}, k_{p d x}, k_{d 1 x}, k_{12 x}, k_{23 x}, k_{3 r x}$ represent the horizontal structural stiffness of cutterhead, bull gear, cutterhead support, front frame, mid frame, and end of frame. $k_{l r y}, k_{r d y}, k_{p d y}, k_{d 1 y}, k_{12 y}, k_{23 y}, k_{3 r y}$ represent the vertical structural stiffness of cutterhead, bull gear, cutterhead support, front frame, mid frame, and end of frame. $k_{m p q}, k_{r l q}, k_{d 1 q}, k_{12 q}, k_{23 q}, k_{3 r q}, k(t)$ represent the torsional stiffness of transmission shaft, cutterhead, front frame, mid frame, end of frame, and the time-varying damping stiffness. $T_{L}, T_{\mathrm{pi}}, F_{x}, F_{y}, F_{L}$ represent the load torque on cutterhead, the input torque of motor, the horizontal unbalanced force on cutterhead, the vertical unbalanced force on cutterhead, and the axial force on cutterhead. 
The above nonlinear simultaneous equations can be expressed in matrix form:

$$
M \ddot{X}+C \dot{X}+K X=F,
$$

where $C, K$ represent the total damping matrix and stiffness matrix, $F$ represents the force vector, $X$ represents the displacement vector, and $M$ represents the mass matrix. These simultaneous equations are solved by Newmark method.

\section{The Dynamic Excitation Simulation of TBM System}

3.1. The Error Excitation. The errors that affect the load distribution between the bull gear and pinion mainly include the manufacturing error of bull gear $E_{r}$, installation error of bull gear $A_{r}$, the tooth thickness deviation of bull gear $\varepsilon_{r}$, the tooth error of bull gear $\delta_{\mathrm{pi}}$, the eccentric error of pinion $E_{\mathrm{pi}}$, the installation error of pinion $A_{\mathrm{pi}}$, and the tooth thickness deviation of pinion $\varepsilon_{\mathrm{pi}}$. The accumulation error on meshing line can be calculated as

$$
\begin{aligned}
\varepsilon_{p r i}(t)= & E_{r} \sin \left(\omega_{r} t+\alpha+\varphi_{i}-\beta_{r}\right) \\
& +A_{r} \sin \left(\alpha+\varphi_{i}-\gamma_{r}\right) \\
& +E_{\mathrm{pi}} \sin \left(\omega_{p} t+\alpha-\beta_{\mathrm{pi}}\right)+A_{\mathrm{pi}} \sin \left(\alpha-\gamma_{\mathrm{pi}}\right) \\
& +\varepsilon_{r}+\varepsilon_{\mathrm{pi}}+\sigma_{r}+\sigma_{\mathrm{pi}} \quad(i=1-8)
\end{aligned}
$$

where $\alpha$ represents meshing contact angle, $\varphi_{i}$ represents phase angle of each pinion, $\beta$ and $\gamma$ represent the phase angle of each error, and $\omega_{p}$ and $\omega_{r}$ represent the angular velocity of pinion and bull gear.

3.2. Elastic Deformation Coordination Conditions. The dynamic model is established based on the structure of Robbins TBM. The bull gear is driven by ten parallel pinions which are connected with motor. The geometry elastic relationship between pinion and bull gear is shown in Figure 4 .

The deformation of pinion and bull gear is projected onto the meshing line, and the total relative elastic deformation can be calculated as

$$
\begin{aligned}
x_{\mathrm{pi}}= & u_{s}+u_{\mathrm{pi}}-x_{s} \sin \left(\varphi_{i}-\alpha\right)+y_{s} \cos \left(\varphi_{i}-\alpha\right) \\
& +\eta_{\mathrm{pi}} \cos \alpha_{t}-\xi_{\mathrm{pi}} \sin \alpha_{t}-\varepsilon_{p r i}(t)
\end{aligned}
$$

where $u_{s}, u_{\mathrm{pi}}$ are the displacement of bull gear and pinion on meshing line, $x_{s}, y_{s}$ are the horizontal and vertical displacement of bull gear, and $\eta_{\mathrm{pi}}, \xi_{\mathrm{pi}}$ are the horizontal and vertical displacement of pinion.

Considering the tooth backlash of gear pair, the meshing clearance nonlinear function can be defined as

$$
f(x, b)= \begin{cases}x-b & x>b \\ 0 & -b \leq x \leq b \\ x+b & x<-b,\end{cases}
$$

where $b$ is half of the value of the tooth backlash and $X$ is the total relative elastic deformation.

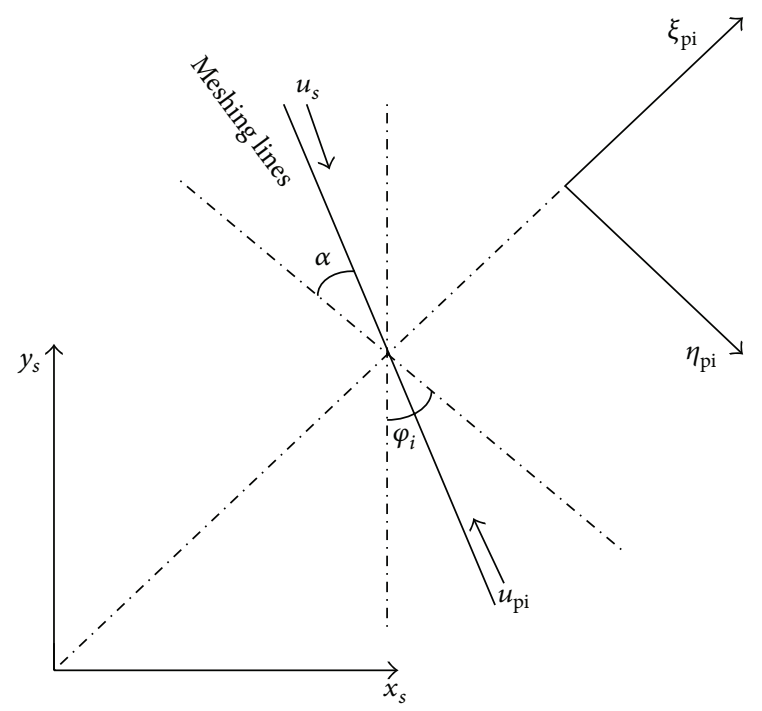

FIGURE 4: The geometry elastic relationship between pinion and bull gear.

3.3. The Calculation of Time-Varying Meshing Stiffness, Damping, and Meshing Force. The time-varying meshing stiffness can be defined as

$$
k(t)=\bar{k}\left(1+s_{f} \sin \left(w_{m} t+\phi\right)\right),
$$

where $s_{f}$ is amplitude coefficient, $w_{m}$ is meshing frequency, $\phi$ is the phase angle of pinion, and $\bar{k}$ is average meshing stiffness.

The time-varying meshing damping can be defined as

$$
C_{p r i}=C p \cdot \dot{x}_{p r i}, \quad C p=2 \xi \sqrt{\frac{k(t) m_{1} m_{2}}{m_{1}+m_{2}}}
$$

where $\xi$ is meshing damping ratio, $m_{1}$ is the mass of bull gear, and $m_{2}$ is the mass of pinion.

The time-varying meshing force can be defined as

$$
F_{p r i}=k(t) \cdot f(x, b) .
$$

3.4. The Calculation of the Support Cylinder Time-Varying Stiffness. The static stiffness of support cylinder is calculated according to the following formula [23]:

$$
K_{y}=E_{y} \cdot\left[\frac{A_{1}^{2}}{V_{l 1}+V_{1}}+\frac{A_{2}^{2}}{V_{l 2}+V_{2}}\right] \text {, }
$$

where $A_{1}, A_{2}$ are the area of two side of the cylinder piston, $V_{1}, V_{2}$ are the hydraulic oil volume in two hydraulic cylinders, and $V_{l 1}, V_{l 2}$ are the total volume of hydraulic oil in two hydraulic pipelines. The values of $V_{l 1}, V_{l 2}$ are almost constant during a boring stoke, and the angle between support cylinder 
TABLE 1: The tunneling parameters and cutterhead parameters.

\begin{tabular}{lccc}
\hline \multicolumn{2}{c}{ Tunneling parameters } & & \multicolumn{2}{c}{ Cutterhead parameters } \\
\hline Advance speed & $2.4 \mathrm{~m} / \mathrm{h}$ & Diameter of cutterhead & $8.53 \mathrm{~m}$ \\
Penetration & $7.8 \mathrm{~mm} / \mathrm{rev}$ & Mass of cutterhead & $152 \mathrm{t}$ \\
Rotating speed & $5.18 \mathrm{RPM}$ & Teeth number of bull gear & 174 \\
Rock mechanical parameters & & Teeth number of pinion & 14 \\
Compressive strength & $93.6 \mathrm{MPa}$ & Number of center cutter & 8 \\
Tunnel depth & $130-1000 \mathrm{~m}$ & Number of inner cutter & 40 \\
Confining pressure & $6-30 \mathrm{MPa}$ & Number of gauge cutter & 12 \\
& & Cutter spacing & $75 \mathrm{~mm}$ \\
\hline
\end{tabular}

and main frame decreases continuously. Therefore, the equivalent stiffness of support cylinder also decreases. The value of this time-varying stiffness can be calculated as

$$
\begin{aligned}
& K_{y}(t)=K_{y} \cdot \cos \theta(t) \\
& \theta(t)=\operatorname{actan}\left(\frac{l_{0} \cdot \sin \theta_{0}}{l_{0} \cdot \cos \theta_{0}+V_{t} \cdot t}\right) .
\end{aligned}
$$

$\theta_{0}$ is the angle between support cylinder and main frame at the beginning of a boring stoke. $l_{0}$ is the length of support cylinder at the beginning of a boring stoke. $V_{t}$ is the elongation velocity of the support cylinder.

3.5. The Calculation of Equivalent Hinge Stiffness. The hinge connection stiffness $K_{1}$ is calculated by the formula below [24]:

$$
K_{1}=\frac{4}{3\left(\sigma_{1}+\sigma_{2}\right)} \sqrt{\frac{R_{1} R_{2}}{R_{1}-R_{2}}} \quad \sigma_{i}=\frac{1-v_{i}^{2}}{E_{i}}, \quad(i=1,2) .
$$

$R_{1}, R_{2}$ represent the radius of the pin and the hinge ear. $\sigma_{1}, \sigma_{2}$ are determined by the materials of pin and hinge ear. The hinge stiffness is determined not only by the connection stiffness but also by the structural stiffness of hinge ear. The structural stiffness of hinge ear is estimated by static analysis. The equivalent hinge stiffness can be calculated by the following formula:

$$
\frac{1}{K_{j}}=\frac{1}{K_{1}}+\frac{1}{K_{2}}
$$

3.6. The Calculation of Bearing Radial Equivalent Stiffness. Pinion bearing mainly bear support radial load, and the radial equivalent stiffness is calculated by empirical formula [25]:

$$
K_{r}=0.34 \times 10^{4} F_{r}{ }^{0.1} Z^{0.9} l^{0.8}(\cos \beta)^{1.9} .
$$

In the formula, $F_{r}$ represents the radial load, $Z$ represents the number of rolling elements, $l$ represents the effective contact length, and $\beta$ represents the rolling element contact angle.

\subsection{The Calculation of Connection Shaft Torsional Stiffness.}

The torsional stiffness of connection shaft between pinion and motor is calculated by the following formula:

$$
k_{-} Q=\frac{G I_{p}}{L} .
$$

In the formula, $I_{p}$ represents inertia moment of the connection shaft, $G$ represents the shear modulus of material, and $L$ represents length of the connection shaft.

3.8. The Calculation of the Other Structural Stiffness and Damping. The equivalent structural stiffness of cutterhead, cutterhead support, main frame, and so forth is determined by finite element method.

The equivalent structural damping is determined by empirical formula:

$$
c=2 \xi \sqrt{m_{e} k_{e}} .
$$

$\xi$ represents the damping ratio; $m_{e}, k_{e}$ represent the equivalent mass and equivalent stiffness of corresponding components.

\section{Engineering Calculation}

This paper takes the Robbins TBM in Liaoning northwest project as example. The tunneling parameters and cutterhead parameters are shown in Table 1.

According to the parameters and the Ls-dyna simulation results, the load time history curve on cutters is obtained. The load on cutterhead is calculated ignoring the load loss in the transmission process, and the load is revised according to the field test data.

4.1. Dynamic Response Analysis. The calculated loads above are taken as input excitation for the dynamic model, and the vibration responses of cutterhead, cutterhead bearing, and so forth in $10 \mathrm{~s}$ are obtained. The response curves are shown in Figure 5.

It shows that (1) the means of axial and horizontal cutterhead vibration reach more than $1 \mathrm{~mm}$, and the mean of vertical vibration is about $50 \%$ of the axial and horizontal vibration. This could be due to the vertical support near the shield of Robbins TBM, and the vertical vibration on the front components of TBM is effectively reduced. (2) The results of horizontal and vertical vibration on cutterhead show a periodicity around $10 \mathrm{~s}$ which is matched with the bull gear rotational period. Obviously, the meshing vibration has a significant influence on the horizontal and vertical vibration on cutterhead. (3) The means of axial vibration on cutterhead, cutterhead bearing, and front frame are around $1.2 \mathrm{~mm}$, 


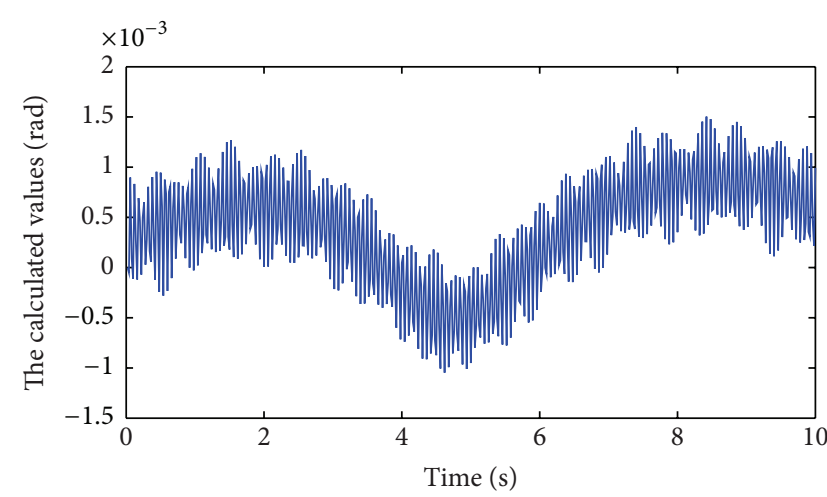

(a) The torsional vibrations of the pinion

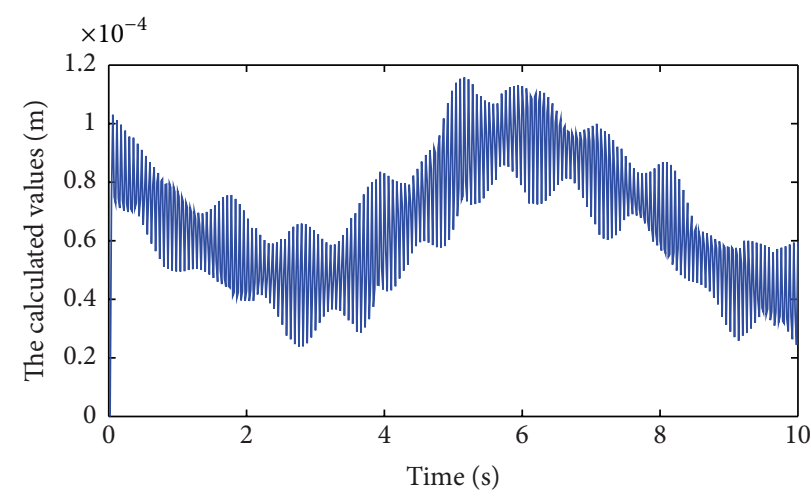

(c) The vertical displacement of cutterhead

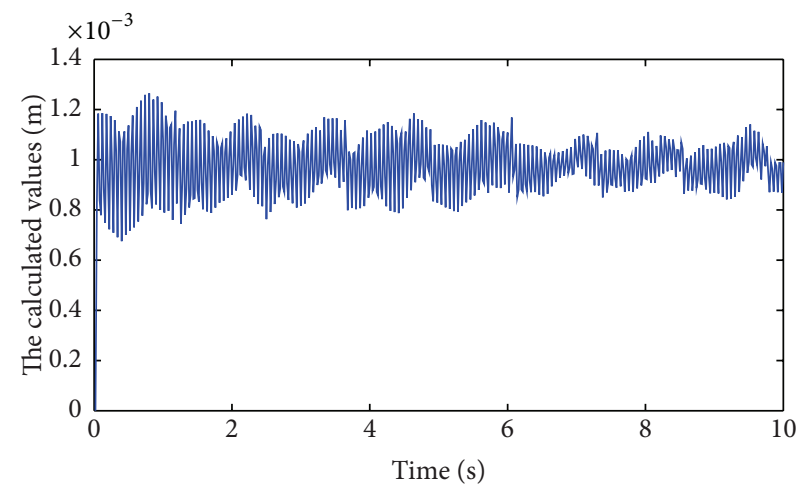

(e) The axial displacement of cutterhead bearing

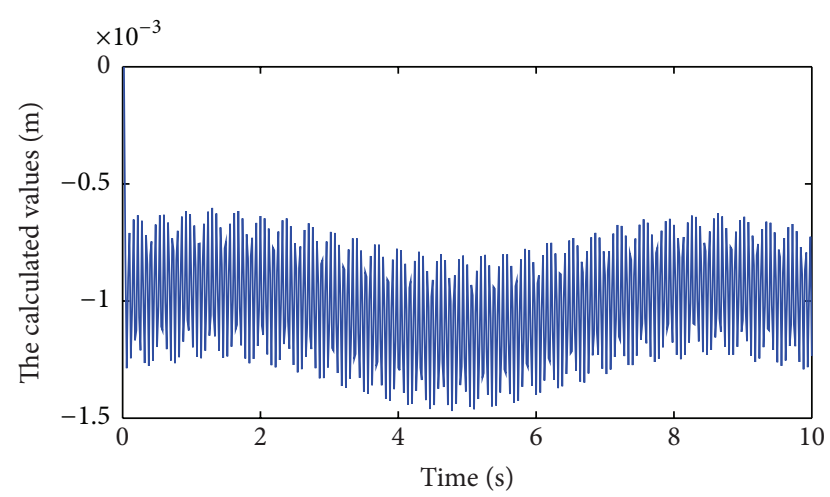

(b) The horizontal displacement of cutterhead

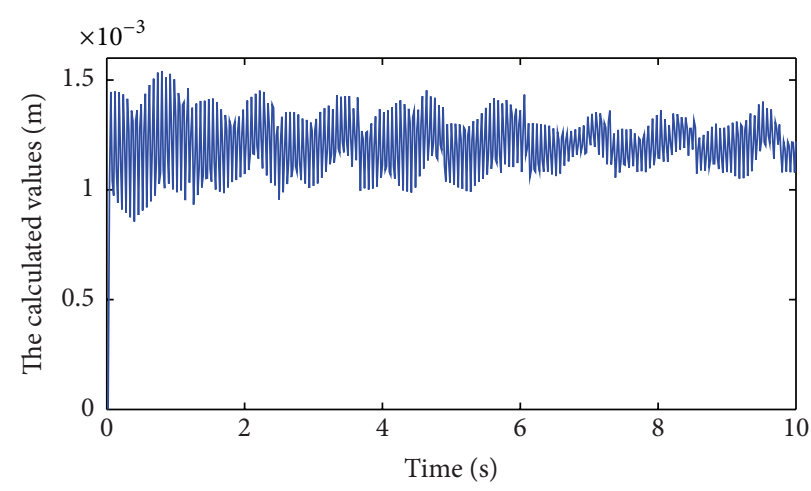

(d) The axial displacement of cutterhead

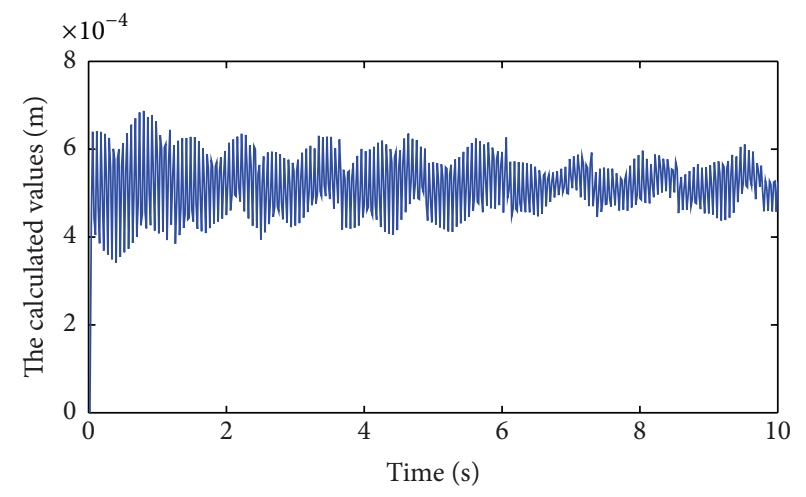

(f) The axial displacement of front frame

FIGURE 5: The response curve of each component.

$1 \mathrm{~mm}$, and $0.5 \mathrm{~mm}$; the values of vibration gradually decrease with the distance from vibration source getting farther.

The spectrogram of input load excitation and response vibration are shown in Figure 6.

It shows that (1) under the time-varying internal and external load excitation, the response frequency of axial and horizontal vibration on cutterhead mainly focuses on 10$20 \mathrm{~Hz}$ and $30-40 \mathrm{~Hz}$. The response frequency of vertical vibration mainly focuses on $0-10 \mathrm{~Hz}$ and $10-20 \mathrm{~Hz}$. It is obvious that the vibration response frequency distribution contains corresponding frequency components of external load excitation. The contrastive results show that the vibration on cutterhead system is mainly forced vibration. (2)
The main responses vibration on cutterhead in 3 directions is less than $40 \mathrm{~Hz}$, and the low order natural frequency of TBM cutterhead system focuses on $50-60 \mathrm{~Hz}$ according to the numerical simulation results. Therefore, severe resonance phenomenon will not appear during boring process.

\section{The Dynamic Model Vibration Based on the Field Test}

5.1. The Establishment of the Vibration Test System. A set of wireless test systems is established in order to obtain the measured dynamic data. The wireless test system consists of three-direction acceleration sensors, acceleration nodes, and 


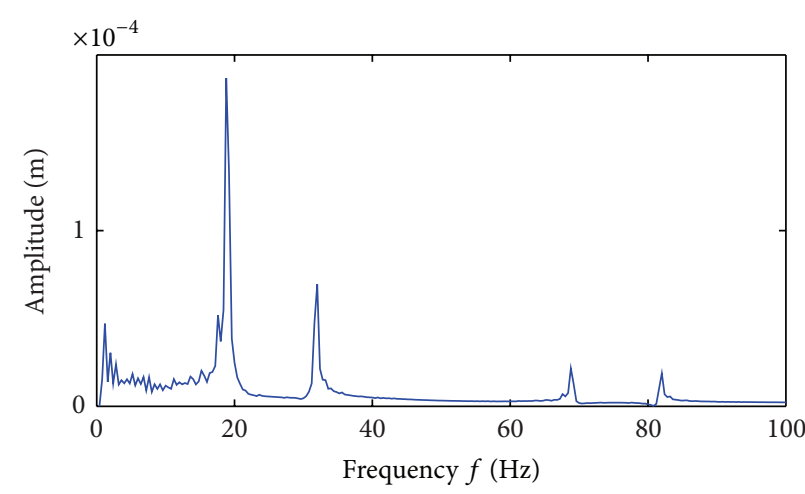

(a) Frequency of cutterhead axial vibration

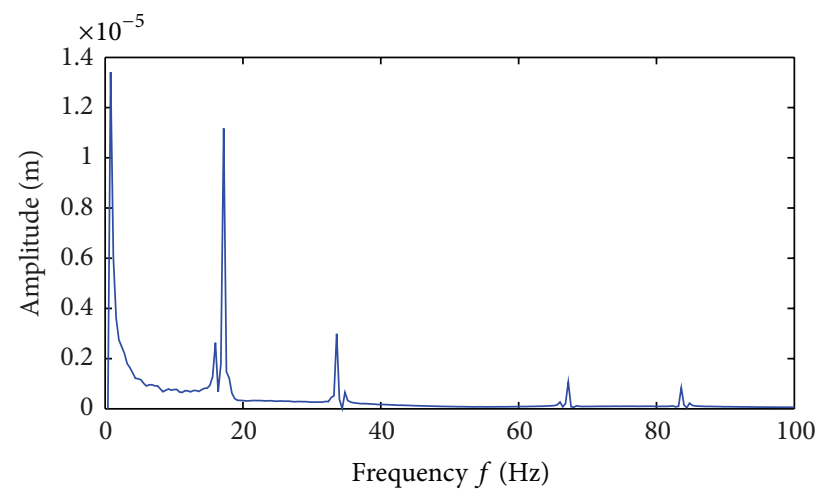

(c) Frequency of cutterhead vertical vibration

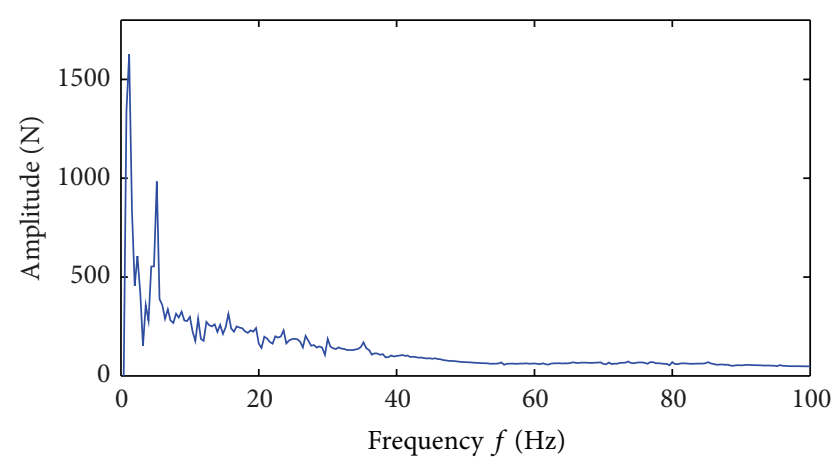

(e) Frequency of horizontal excitation

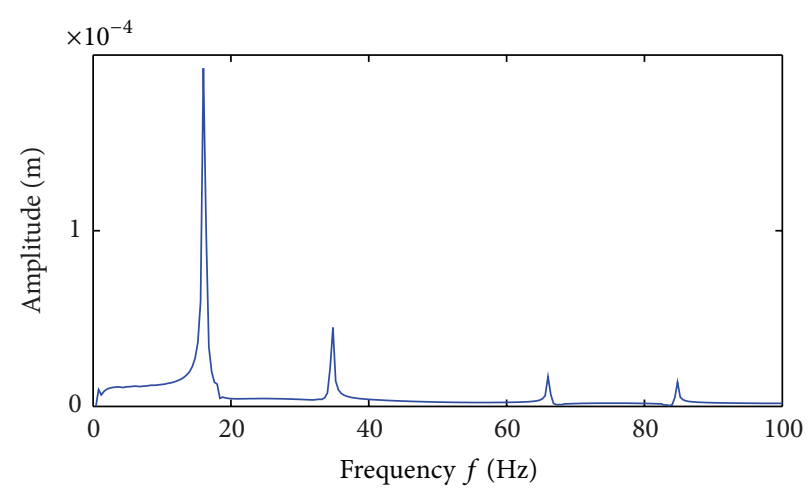

(b) Frequency of cutterhead horizontal vibration

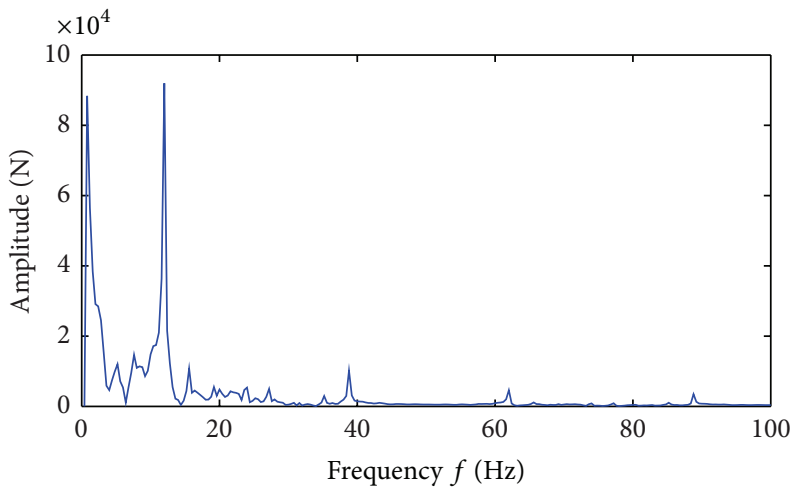

(d) Frequency of axial excitation

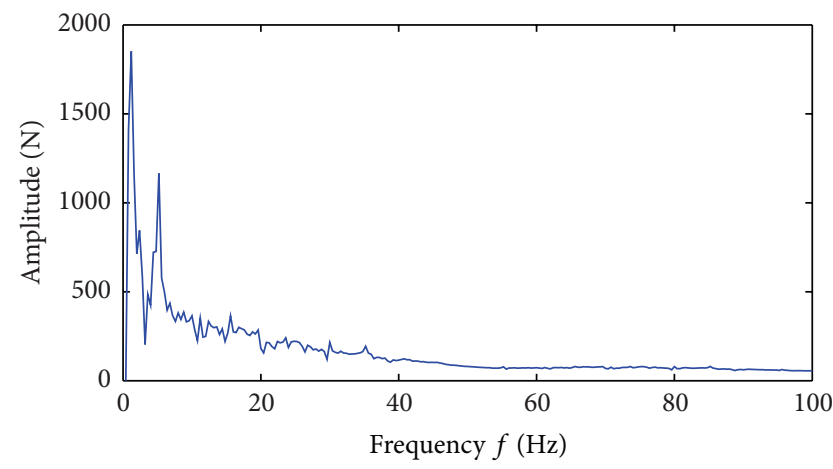

(f) Frequency of vertical excitation

FIgURE 6: The spectrogram.

wireless receiver. The composition diagram of the wireless test system is shown in Figure 8. The test acceleration sensors are placed on the cutterhead, cutterhead bearing flange, mid frame, and the end of support cylinder, and the test points are numbered mpl, mp2, mp3, and mp4 as shown in Figure 7. The field test photos are shown in Figure 8. Considering the bad working conditions inside the cutterhead, the corresponding acceleration sensor is fixed in a special protective cap. Due to the rotation of cutterhead and the complex structure, the signals from the cutterhead will decay sharply. In test, the positions of the signal transmitting antenna and the signal receiver are appropriately adjusted. It makes the vibration signal from cutterhead be stably received. Thus, the primary vibration data of cutterhead is obtained.
5.2. The Analysis of Measured Data. The test points on cutterhead and mid frame are defined by three-directions acceleration sensors, and the test points on cutterhead bearing flange and the end of the support cylinder are defined by uniaxial acceleration sensor. Take some of the test data as example, and Figure 9 shows the measured values of each component in comparison with the corresponding calculated values.

As can be seen from Figure 9, (1) in normal boring conditions, the three-directions acceleration vibration amplitudes are all around 1.5-2.0 g. (2) The axial and horizontal acceleration vibration amplitudes are close to $0.6 \mathrm{~g}$, and the vertical acceleration vibration amplitude is significantly smaller, which is about $1 / 2$ of the former. (3) The vibration 


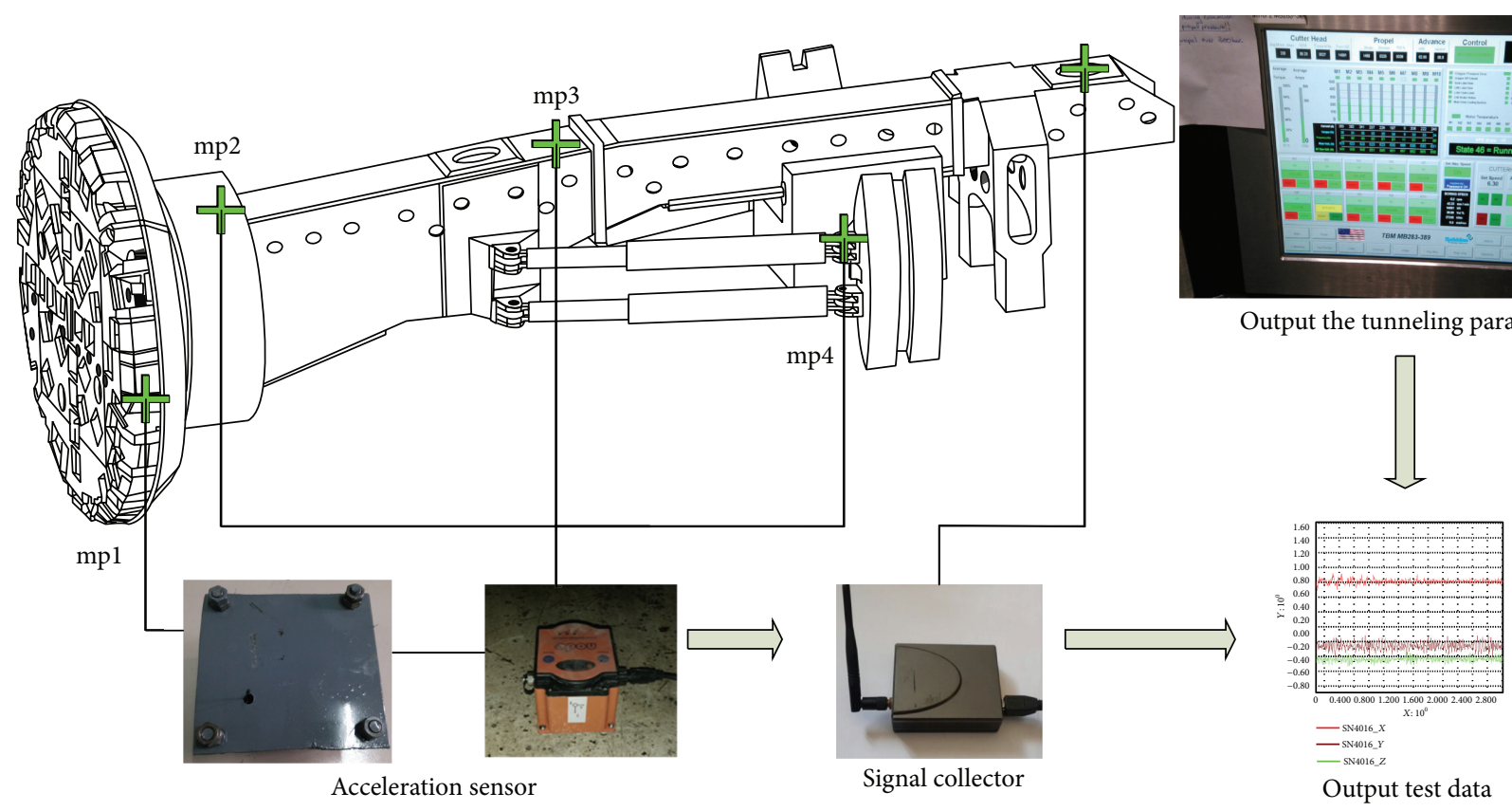

FIgURE 7: The composition diagram of the wireless test system.

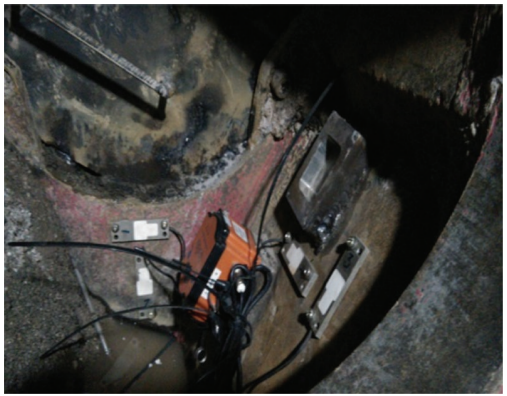

(a) Cutterhead

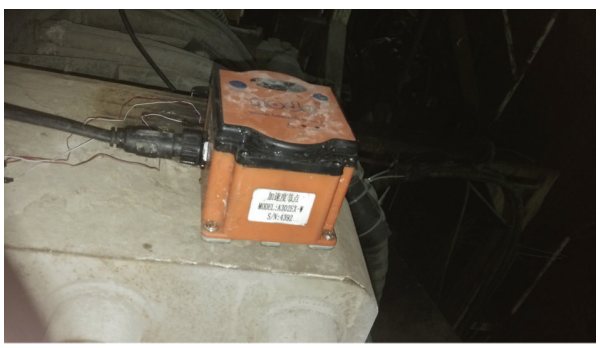

(c) Mid frame

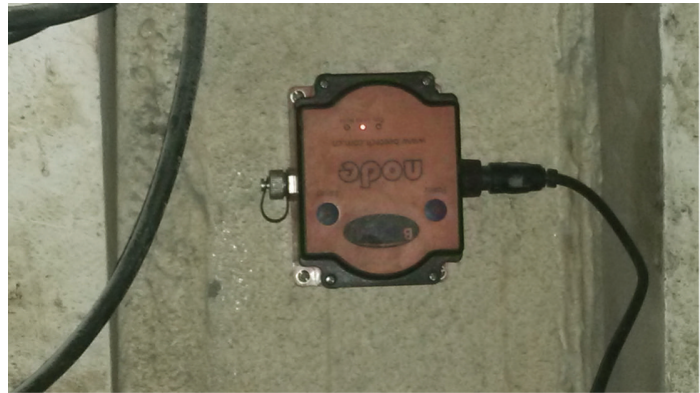

(b) Cutterhead bearing flange

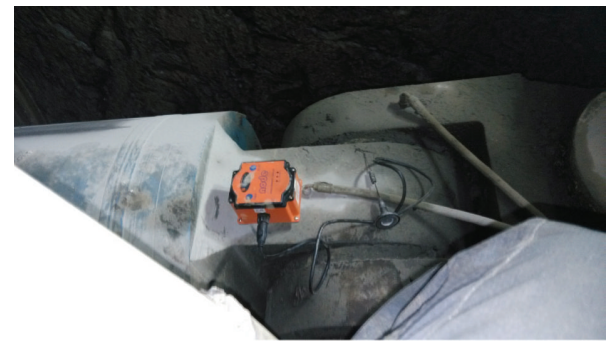

(d) End of the support cylinder

FIgURE 8: The field test photos.

condition of support cylinder is close to that of the main frame whose vibration amplitude is around $0.6 \mathrm{~g}$.

Some random events often occur during the field test. For example, the dropped rocks shock the cutterhead. These external influences present a series of high peak in the test data. In order to avoid the random events producing great influence on the dynamic analysis, the rain flow count method is used to assess how well the calculated values fit the measured values. Firstly, the measured values and the calculated values are divided into several intervals, and then the peak and average values in each interval are computed. Finally, the mean and amplitude of these statistics are calculated to measure the calculation error. The rain flow count statistics for each test point are listed in Table 2.

It can be seen from the figure that, among the several test point, the maximal calculation error of the mean of vibration amplitude is $36.90 \%$ while the maximal calculation error of the MSE of vibration amplitude is $40.41 \%$. These results 


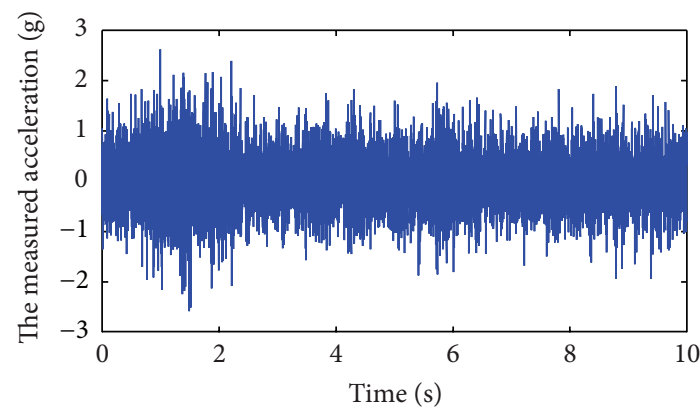

(a) The measured axial acceleration of cutterhead

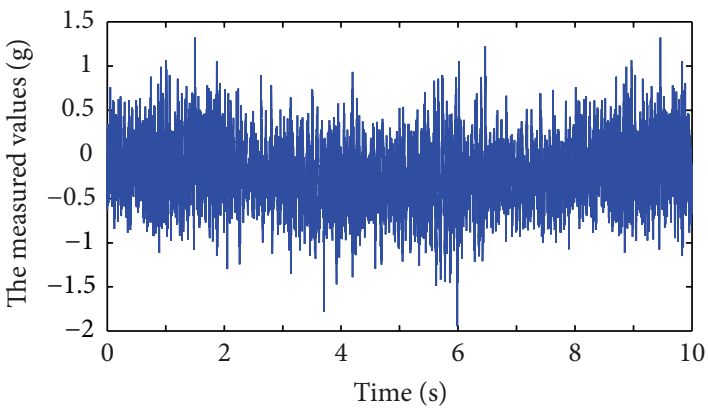

(c) The measured horizontal acceleration of cutterhead

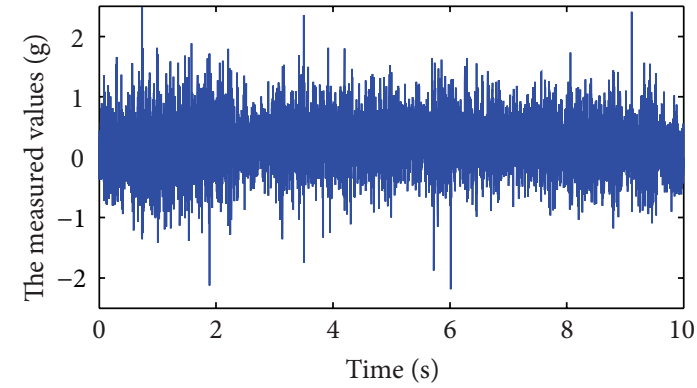

(e) The measured values of cutterhead vertical acceleration

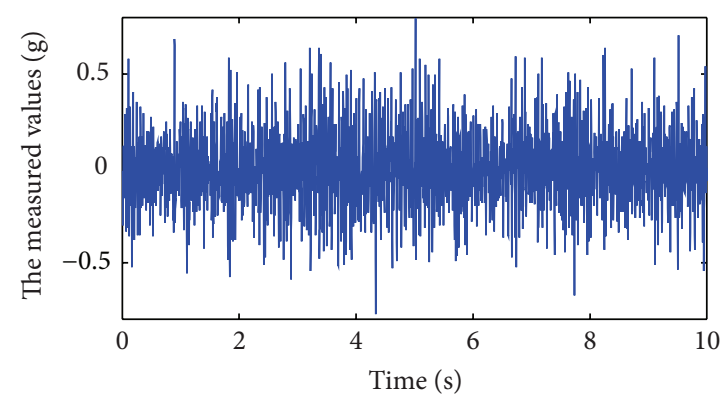

(g) The measured values of mid grider axial acceleration

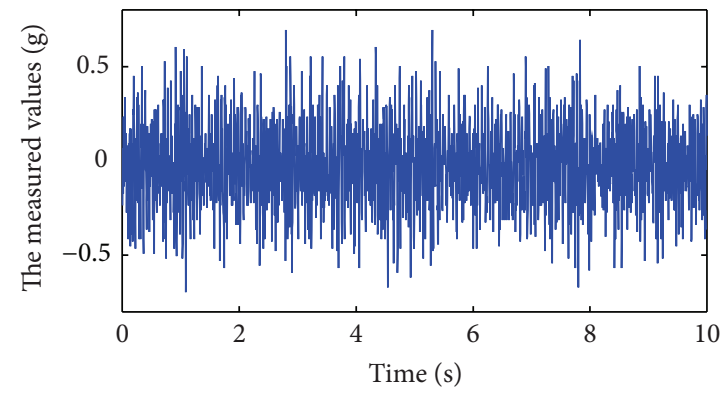

(i) The measured values of mid grider horizontal acceleration

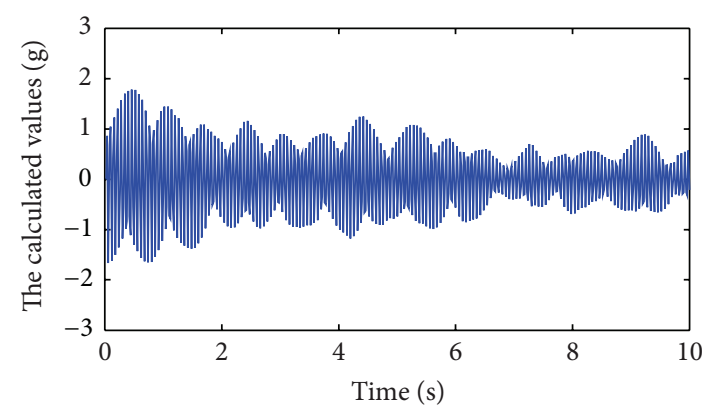

(b) The calculated values of axial acceleration of cutterhead

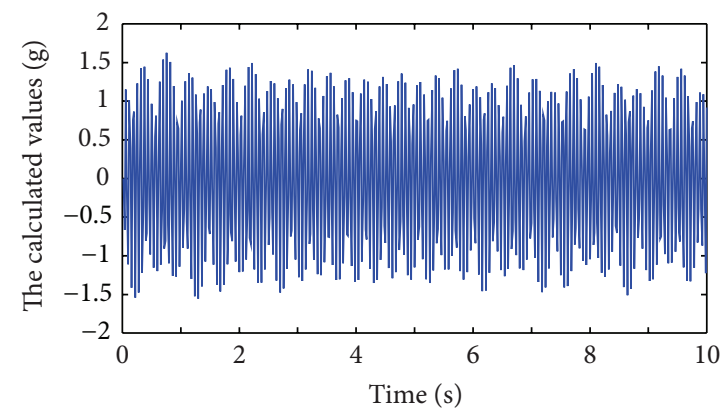

(d) The calculated values of cutterhead horizontal acceleration

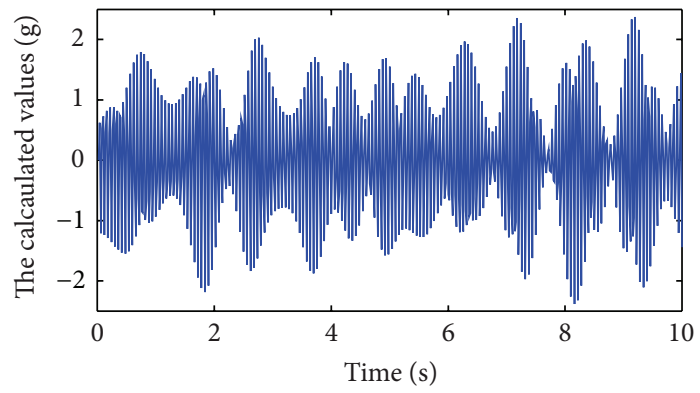

(f) The calculated values of cutterhead vertical acceleration

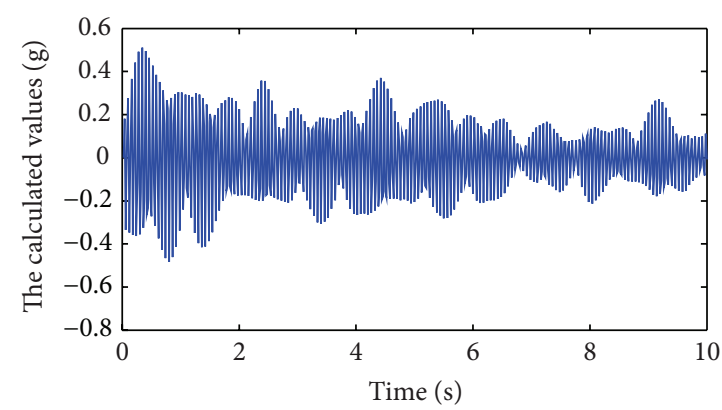

(h) The calculated values of mid grider axial acceleration

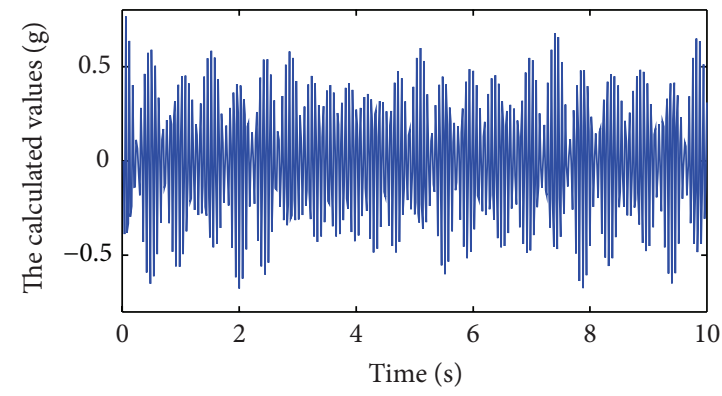

(j) The calculated values of mid grider horizontal acceleration 


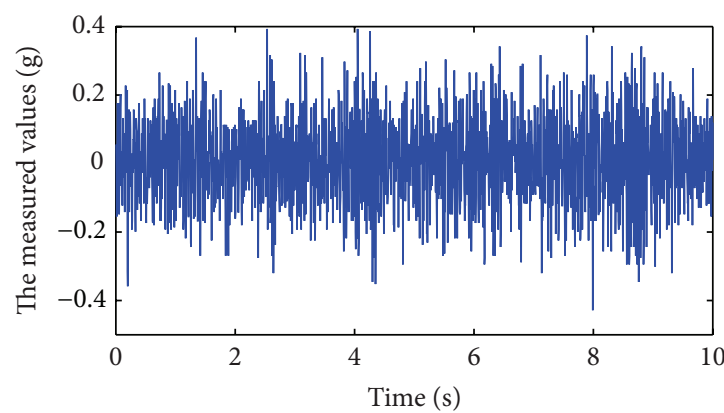

(k) The measured values of mid grider vertical acceleration

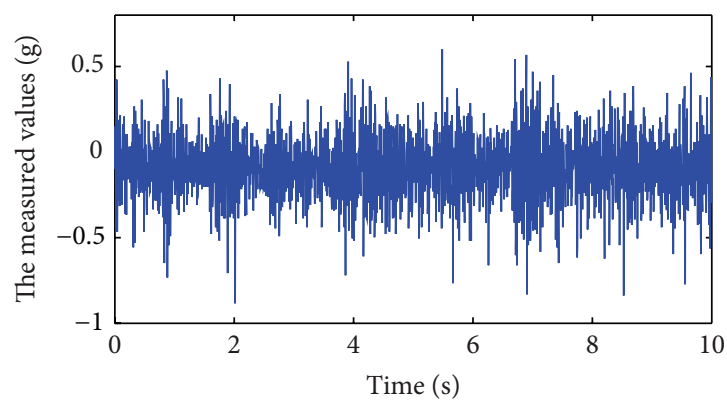

(m) The measured values of support cylinder acceleration

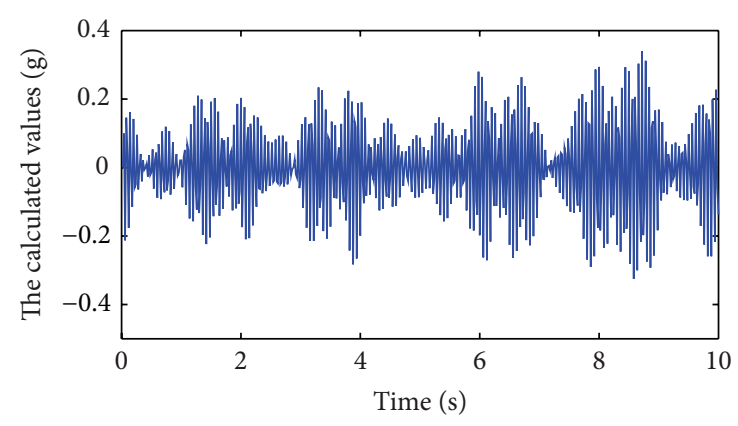

(1) The calculated values of mid grider vertical acceleration

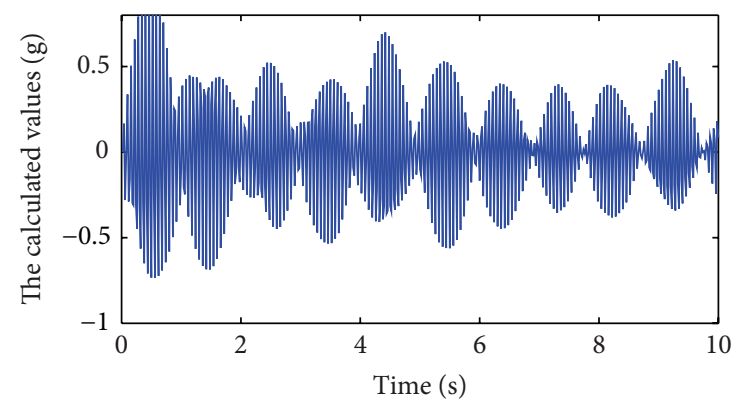

(n) The calculated values of support cylinder acceleration

FIGURE 9: The measured values and calculated values of each component.

TABLE 2: The rain flow count statistics for each test point.

\begin{tabular}{|c|c|c|c|c|c|c|}
\hline & \multicolumn{2}{|c|}{ The measured values } & \multicolumn{2}{|c|}{ The calculated values } & \multicolumn{2}{|c|}{ Error } \\
\hline & $\begin{array}{l}\text { The mean of } \\
\text { amplitude }\end{array}$ & $\begin{array}{l}\text { MSE of the } \\
\text { amplitude }\end{array}$ & $\begin{array}{l}\text { The mean of } \\
\text { amplitude }\end{array}$ & $\begin{array}{l}\text { MSE of the } \\
\text { amplitude }\end{array}$ & $\begin{array}{l}\text { The mean of } \\
\text { amplitude }\end{array}$ & $\begin{array}{l}\text { MSE of the } \\
\text { amplitude }\end{array}$ \\
\hline Cutterhead's axial acceleration & 0.1323 & 0.1277 & 0.1610 & 0.1793 & $21.69 \%$ & $40.41 \%$ \\
\hline $\begin{array}{l}\text { Cutterhead's horizontal } \\
\text { acceleration }\end{array}$ & 0.3079 & 0.3026 & 0.3006 & 0.2701 & $2.3 \%$ & $10.74 \%$ \\
\hline Cutterhead's vertical acceleration & 0.2644 & 0.2518 & 0.2718 & 0.2696 & $2.80 \%$ & $7.07 \%$ \\
\hline Mid grider's axial acceleration & 0.0636 & 0.0633 & 0.0398 & 0.0419 & $37.42 \%$ & $33.81 \%$ \\
\hline $\begin{array}{l}\text { Mid grider's horizontal } \\
\text { acceleration }\end{array}$ & 0.0672 & 0.0698 & 0.0920 & 0.0756 & $36.90 \%$ & $8.31 \%$ \\
\hline Mid grider's vertical acceleration & 0.0350 & 0.0350 & 0.0347 & 0.0399 & $0.85 \%$ & $14.00 \%$ \\
\hline $\begin{array}{l}\text { Cutterhead bearing's axial } \\
\text { acceleration }\end{array}$ & 0.1895 & 0.1967 & 0.1363 & 0.1500 & $28.07 \%$ & $23.74 \%$ \\
\hline Support cylinder's acceleration & 0.0568 & 0.0578 & 0.0730 & 0.0688 & $28.52 \%$ & $19.03 \%$ \\
\hline
\end{tabular}

show that the dynamic model is accurate and reasonable. Particularly, the small calculation error of test point 4 (the end of support cylinder) proves that the calculation of the cylinder stiffness is reasonable.

5.3. The Stiffness Distribution of TBM Machine. The stiffness distribution of the TBM machine is determined by the dynamic model. The stiffness of each component is shown in Table 3 except the time-varying support cylinder stiffness and the time-varying damping stiffness.

As can be seen from Table 3, (1) the axial stiffness of each component is of the order of $1 \times 10^{10} \mathrm{~N} / \mathrm{m}$, and the hinge is the weakest part in axial direction with the equivalent stiffness being $1 \times 10^{8} \mathrm{~N} / \mathrm{m}$; (2) the horizontal and vertical stiffness of cutterhead bearing are of the order of $1 \times 10^{12} \mathrm{~N} / \mathrm{m}$; it is the major part to bear the horizontal and vertical load. The bull gear is the weakest part in horizontal and vertical direction; (3) the weakest part in torsional direction is the connection shaft between pinion and motor, and stiffness of this part should be enhanced in the structure design.

\section{Conclusions}

A dynamic coupling nonlinear model includes cutterhead system and propulsion system is established by concentrated mass method. The Newmark method is used to solve 
TABLE 3: The stiffness distribution of the TBM machine.

\begin{tabular}{lccccccc}
\hline \multicolumn{2}{c}{ Axial direction } & \multicolumn{2}{c}{ Horizontal direction } & Vertical direction & Torsion \\
\hline Cutterhead & $1 \times e^{10}$ & Cutterhead & $1 \times e^{10}$ & Cutterhead & $1 \times e^{10}$ & Cutterhead & $1 \times e^{12}$ \\
Cutterhead bearing & $1 \times e^{10}$ & Cutterhead bearing & $1 \times e^{12}$ & Cutterhead bearing & $1 \times e^{12}$ & Cutterhead support & $1 \times e^{9}$ \\
Hinge stiffness & $1 \times e^{8}$ & Bull gear & $1 \times e^{9}$ & Bull gear & $1 \times e^{9}$ & Connection shaft & $1 \times e^{8}$ \\
Front frame & $1 \times e^{10}$ & Frond frame & $1 \times e^{10}$ & Front frame & $1 \times e^{10}$ & Front frame & $1 \times e^{9}$ \\
Mid frame & $1 \times e^{10}$ & Mid frame & $1 \times e^{10}$ & Mid frame & $1 \times e^{10}$ & Mid frame & $1 \times e^{9}$ \\
The end of frame & $1 \times e^{10}$ & The end of frame & $1 \times e^{10}$ & The end of frame & $1 \times e^{10}$ & The end of frame & $1 \times e^{9}$ \\
Cutterhead support & $1 \times e^{10}$ & Pinion & $1 \times e^{9}$ & Pinion & $1 \times e^{9}$ & \\
& & & The support near shield & $1 \times e^{12}$ & \\
\hline
\end{tabular}

differential equations for TBM system. The load of rock fragmentation on cutterhead simulated by ls-dyna is used as the input load. The inherent frequency and dynamic response of TBM are calculated. Then, the calculated values and the measured values are compared and analyzed:

(1) The calculated results and tested data indicate that the maximum amplitude of horizontal and vertical cutterhead acceleration reaches around $2 \mathrm{~g}$. The amplitude of axial and horizontal mid frame acceleration is around $0.6 \mathrm{~g}$, but the vertical one is about $0.3 \mathrm{~g}$, which is significantly smaller. It indicates that, for the perspective of acceleration, the support beneath the shield of Robbins TBM decreases the vertical vibration of the main frame significantly, but the influence on vertical vibration of the cutterhead is not that obvious.

(2) The relative elastic deformation expression is deduced which establishes a deformation relationship between the torsional DOF, the horizontal DOF, and the vertical DOF of each mass. The result of dynamic calculation shows that the torsional, horizontal, and vertical vibration period of each mass contain a period of $10 \mathrm{~s}$ which fits the input torsional period of the bull gear. The periodicity of horizontal DOF is more significant than vertical DOF. It shows that the torsional DOF affects the horizontal DOF more than the vertical DOF.

(3) By comparing the input load and the dynamic response frequency, it can be seen that the response frequency contains corresponding frequency components of external load excitation. The possibility of resonance is ruled out by comparing the inherent frequency with the response frequency of the cutterhead. It also shows that the vibration of cutterhead and so forth are forced vibration.

(4) This paper determines the stiffness distribution of TBM and confirms that the weakest components in the TBM axial, horizontal, vertical, and torsional DOF are the hydrocylinder hinge, bull gear, and the connection shaft between pinion and motor. These weak parts should be considered comprehensively in the antivibration design of the TBM.
Future research will focus on the following aspects.

(1) The different influence that supports model impact on the vibration of TBM will be studied based on the dynamic model.

(2) The mass migration and gravity will be considered when establishing the dynamic model.

(3) The TBM stiffness distribution will be optimized based on the vibration response.

\section{Conflict of Interests}

The authors declare that there is no conflict of interests regarding the publication of this paper.

\section{Acknowledgments}

This work is supported by the National Natural Science Foundation of China $(51375001,51309045)$ and Development Program of China (973 Program) (Grant no. 2013CB035400). The authors gratefully acknowledge the reviewers and editors for their helpful comments and suggestions, which have improved the research.

\section{References}

[1] Promotion Center for Science \& Technology Achievements of Ministry of Water Resources, Full Face Rock Tunnel Boring Machine (TBM), Petroleum Industry Press, Beijing, China, 2005.

[2] M. Cigla and L. Ozdemir, "Computer modeling for improved production of mechanical excavators," in Proceedings of the Society for Mining, Metallurgy and Exploration Annual Meeting (SME '00), Salt Lake City, Utah, USA, February 2000.

[3] E. Schlangen and J. G. M. van Mier, "Simple lattice model for numerical simulation of fracture of concrete materials and structures," Materials and Structures, vol. 25, no. 9, pp. 534-542, 1992.

[4] J. Rostami, L. Ozdemir, and B. Nilson, "Comparison between CSM and NTH hard rock TBM performance prediction models," in Proceedings of the Institute of Shaft Drilling Technology (ISDT) Annual Technical Conference, Las Vegas, Nev, USA, May 1996. 
[5] Z. Zhang and C. Mao, "Statistical analysis of dis cutter pressing mark results about full face rock tunnel boring machine," Modern Electic Power, vol. 13, no. 1, pp. 63-68, 1996.

[6] H. Zhang, "Study on numerical simulations of performance of tunnel boring machine (TBM)," Tunnel Construction, vol. 26, supplement 2, pp. 1-7, 2006.

[7] A. E. Samuel and L. P. Seow, "Disc force measurements on a full-face tunnelling machine," International Journal of Rock Mechanics and Mining Sciences \& Geomechanics Abstracts, vol. 21, no. 2, pp. 83-96, 1984.

[8] Z. X. Zhang, S. Q. Kou, and P.-A. Lindqvist, "In-situ measurements of cutter forces on boring machine at Äspö Hard Rock Laboratory. Part II. Characteristics of cutter forces and examination of cracks generated," Rock Mechanics and Rock Engineering, vol. 36, no. 1, pp. 63-83, 2003.

[9] Z. Zhang, J. Zhou, and R. Liu, "Analysis of the mechanic model of cutterhead bearing of a full face rock tunnel boring machine," Journal of Basic Science and Engineering, vol. 18, no. 1, supplement, pp. 225-232, 2010.

[10] Z. Zhang and D. Ye, "Determination and analysis of cutter pitch on rock tunneller," Design and Calculation, no. 11, pp. 11-12, 2002.

[11] Q. Tang, Z.-J. Xu, Y.-M. Xia, and K. Zhang, "Numerical study on mode of breaking rock by TBM cutter in two cutting orders," Journal of Central South University, vol. 43, no. 3, pp. 940-946, 2012.

[12] Y. Xia, T. Ouyang, X. Zhang, and D. Luo, "Mechanical model of breaking rock and force characteristic of disc cutter," Journal of Central South University, vol. 19, no. 7, pp. 1846-1852, 2012.

[13] Q. Tan, N. Yi, Y. Xia, Z. Xu, Y. Zhu, and J. Song, "Reserch on rock dynamic fragmentation characteristics by TBM cutters and cutter spacing optimization," Chinese Journal of Rock Mechanics and Engineering, vol. 31, no. 12, pp. 2453-2464, 2012.

[14] J. Huo, W. Sun, J. Chen et al., "Disc cutters' layout design of the full-face rock tunnel boring machine (TBM) using a cooperative coevolutionary algorithm," Journal of Mechanical Science and Technology, vol. 25, no. 2, pp. 415-427, 2011.

[15] J. Huo, Y. Shi, H. Teng, R. Chai, and L. Zhang, "Cutter layout design of full-face rock tunnel boring machine (TBM)," China Mechanical Engineering, vol. 19, no. 15, pp. 1832-1836, 2008.

[16] Z. Li, J. Huo, W. Sun et al., "Cutterhead structure optimal design of the full-face rock tunnel boring machine," Machine Design \& Research, vol. 27, no. 1, pp. 83-86, 2011.

[17] H. Zhang and N. Zhang, "Brief discussion on cutterhead vibration of type 803E TBM," Tunnel Construction, vol. 27, no. 6, pp. 76-78, 2007.

[18] K. Zhang, Study on dynamic characteristics of redundantly driven revolving system of shield TBM [Ph.D. thesis], Shanghai Jiao Tong University, Shanghai, China, 2011.

[19] J. Cai, Dynamic performance analysis and parameter optimization of wind power speed-up machine planetary gear trains [M.S. thesis], Dalian University of Technology, Dalian, China, 2012.

[20] J. Yang, Study on dynamics characteristics of planetary gear transmission system of wind turbine under varying loads [Ph.D. thesis], Chongqing University, Chongqing, China, 2012.

[21] W. Sun, J. Ling, J. Huo, L. Guo, X. Zhang, and L. Deng, "Dynamic characteristics study with multidegree-of-freedom coupling in TBM cutterhead system based on complex factors," Mathematical Problems in Engineering, vol. 2013, Article ID 635809, 17 pages, 2013.
[22] J. Huo, H. Wu, J. Yang, W. Sun, G. Li, and X. Sun, "Multidirectional coupling dynamic characteristics analysis of TBM cutterhead system based on tunneling field test," Journal of Mechanical Science and Technology, vol. 8, no. 29, pp. 1-16, 2015.

[23] Y. Dai, "The cylinder hydraulic stiffness calculation," Nonferrous Metals Design, vol. 26, no. 1, pp. 61-62, 1999.

[24] H. Zhao, Q. Chen, and K. Huang, "Fractal model of normal contact stiffness between two cylinders' joint interfaces," Journal of Mechanical Engineering, vol. 47, no. 7, pp. 53-58, 2011.

[25] S. Deng and Q. Jia, Design Principles of Rolling Bearings, Standards Press of China, Beijing, China, 2008. 

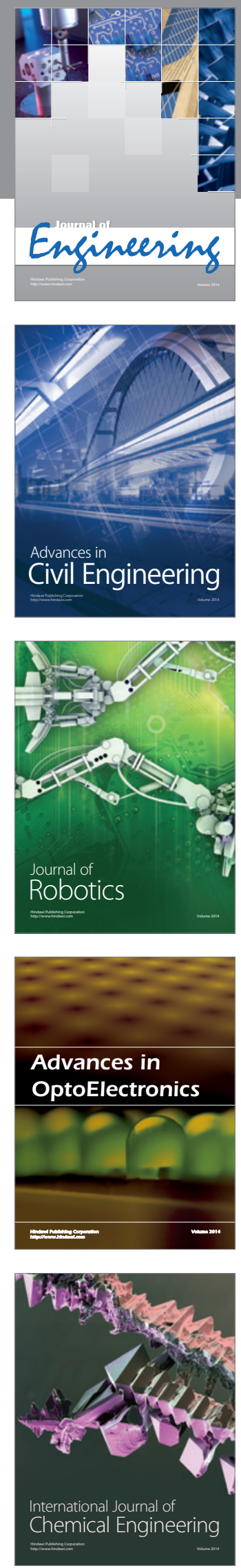

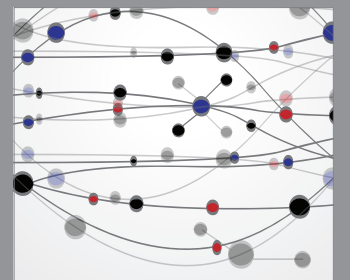

The Scientific World Journal
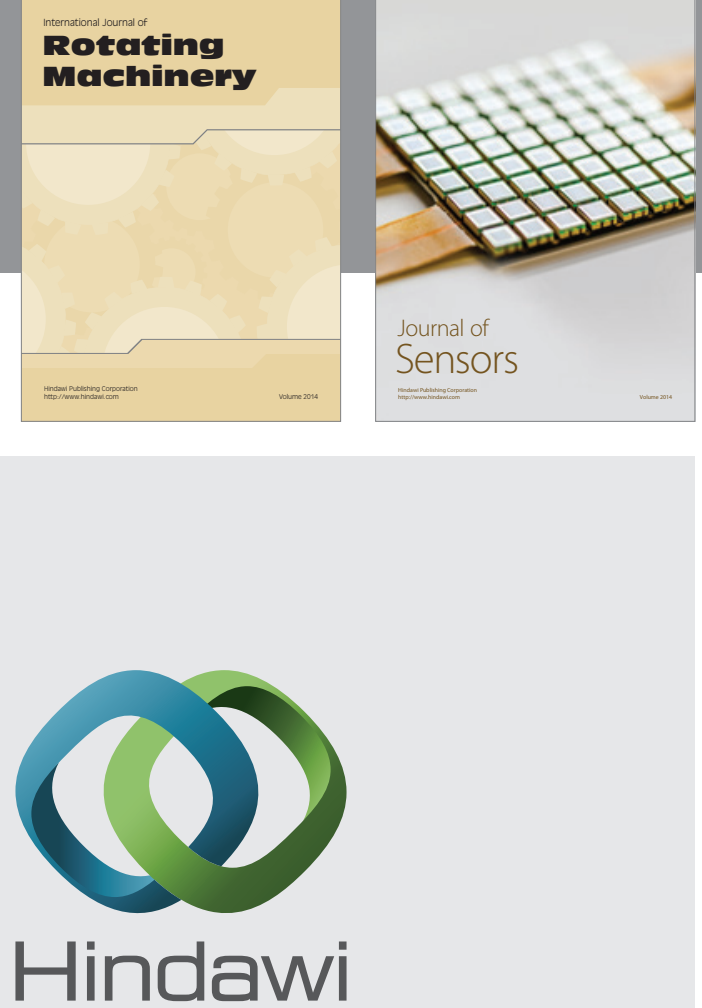

Submit your manuscripts at http://www.hindawi.com
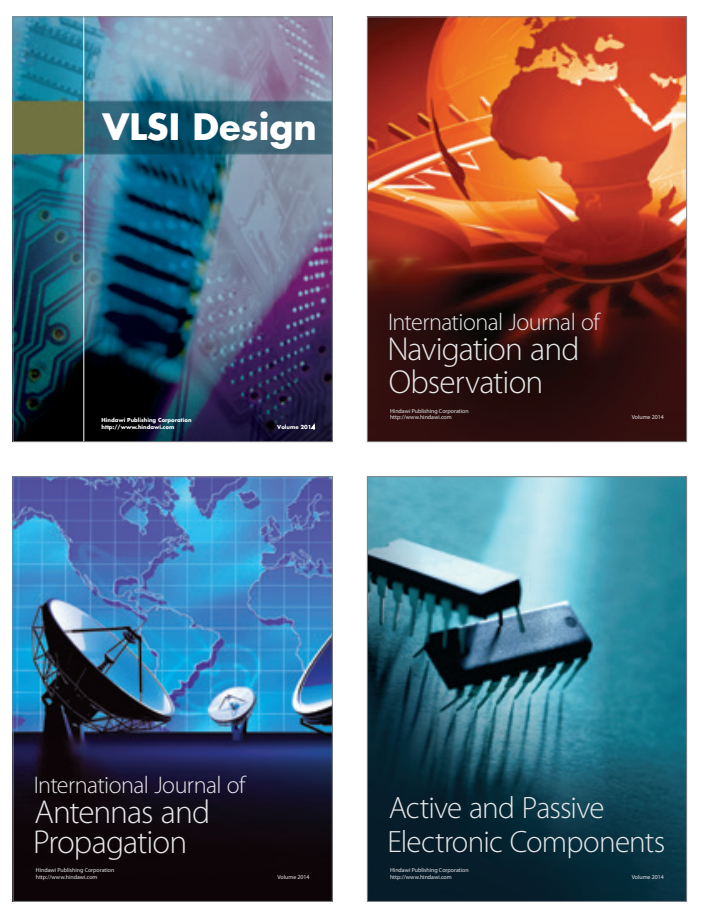
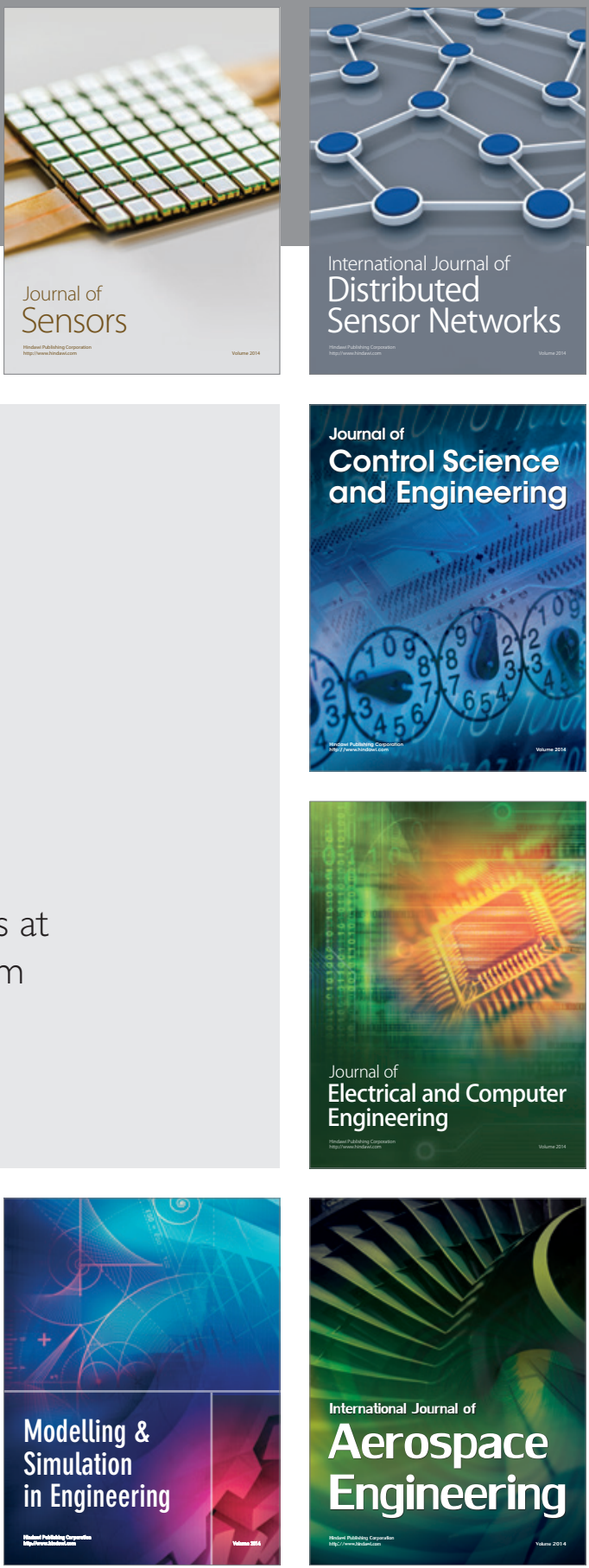

Journal of

Control Science

and Engineering
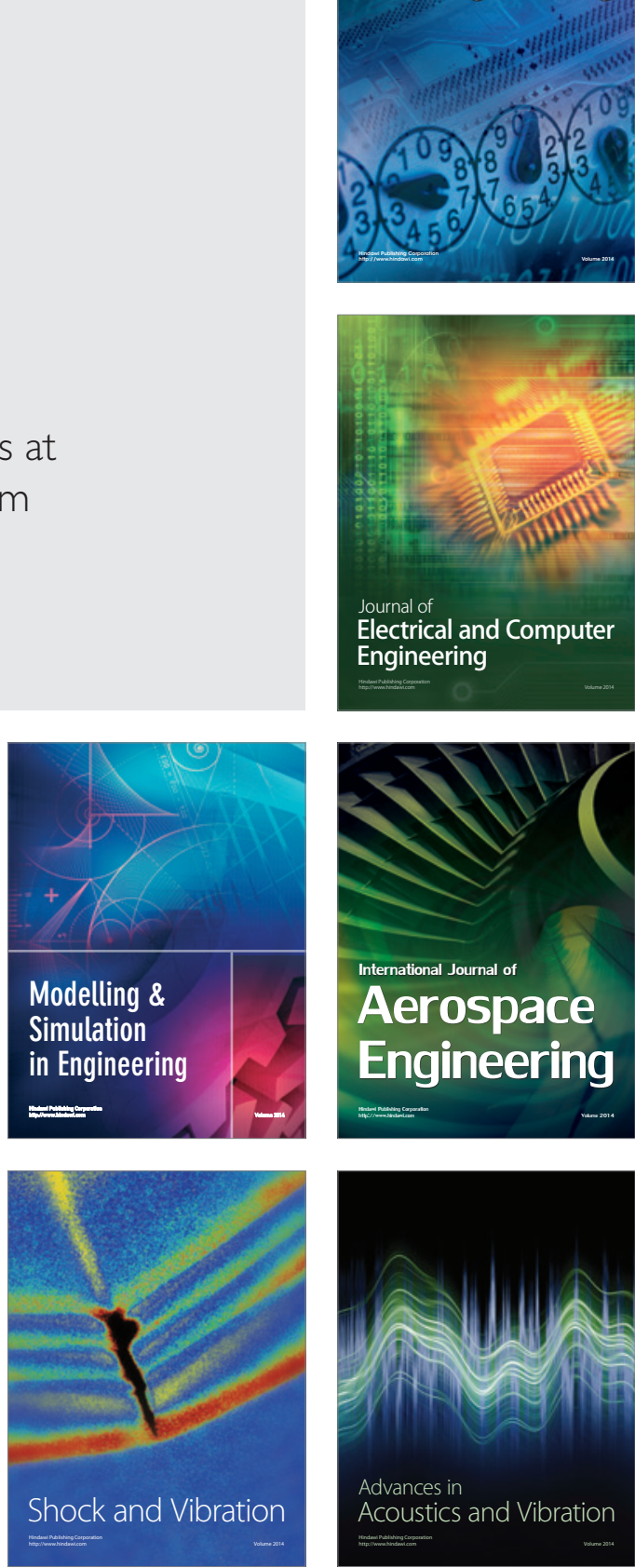